\title{
DIAGNOSIS OF ENDOCRINE DISEASE Congenital hypothyroidism: update and perspectives
}

\section{Peters', A S P van Trotsenburg'2 and N Schoenmakers ${ }^{3}$}

${ }^{1}$ Department of Endocrinology, Great Ormond Street Hospital for Children, London, UK, 'Emma Children's, Amsterdam UMC, University of Amsterdam, Pediatric Endcorinology, Amsterdam, the Netherlands, and ${ }^{3}$ University of Cambridge Metabolic Research Laboratories, Wellcome Trust-Medical Research Council Institute of Metabolic Science, Addenbrooke's Hospital, Cambridge, UK
Correspondence should be addressed to N Schoenmakers

Email

naaa2@cam.ac.uk

\begin{abstract}
Congenital hypothyroidism $(\mathrm{CH})$ may be primary, due to a defect affecting the thyroid gland itself, or central, due to impaired thyroid-stimulating hormone (TSH)-mediated stimulation of the thyroid gland as a result of hypothalamic or pituitary pathology. Primary $\mathrm{CH}$ is the most common neonatal endocrine disorder, traditionally subdivided into thyroid dysgenesis (TD), referring to a spectrum of thyroid developmental abnormalities, and dyshormonogenesis, where a defective molecular pathway for thyroid hormonogenesis results in failure of hormone production by a structurally intact gland. Delayed treatment of neonatal hypothyroidism may result in profound neurodevelopmental delay; therefore, $\mathrm{CH}$ is screened for in developed countries to facilitate prompt diagnosis. Central congenital hypothyroidism $(\mathrm{CCH})$ is a rarer entity which may occur in isolation, or (more frequently) in association with additional pituitary hormone deficits. $\mathrm{CCH}$ is most commonly defined biochemically by failure of appropriate TSH elevation despite subnormal thyroid hormone levels and will therefore evade diagnosis in primary, TSH-based $\mathrm{CH}$-screening programmes. This review will discuss recent genetic aetiological advances in $\mathrm{CH}$ and summarize epidemiological data and clinical diagnostic challenges, focussing on primary $\mathrm{CH}$ and isolated $\mathrm{CCH}$.
\end{abstract}

\section{Introduction}

Primary congenital hypothyroidism $(\mathrm{CH})$ occurs due to defective thyroid gland development or hormone biosynthetic function and is traditionally sub-classified as thyroid dysgenesis (TD) or dyshormonogenesis. TD refers to a spectrum of aberrant thyroid gland development, most commonly involving thyroid ectopy, an abnormally

\section{Invited author's profile}

Nadia Schoenmakers is a Wellcome Trust Intermediate Clinical Fellow and Principal Investigator at the Wellcome Trust-MRC Institute of Metabolic Science, University of Cambridge (UK), as well as an Honorary Consultant Endocrinologist at Addenbrooke's Hospital, Cambridge. Her research group investigates the genetic basis of congenital hypothyroidism, using candidate gene and next generation sequencing approaches to identify known and novel genetic causes of congenital primary and central hypothyroidism. She aims to gain new insights into thyroid biology by identifying and functionally characterising genes causing these disorders; and then to translate these discoveries into genetic diagnostic and clinical practice.

Published by Bioscientifica Ltd. 
situated and mostly small thyroid gland. Complete absence of the thyroid gland (athyreosis) affects 20-30\% of TD cases and a small minority exhibit a normally located but hypoplastic thyroid (1). Dyshormonogenesis refers to failure of thyroid hormone production by a normally located, sometimes goitrous thyroid gland in which the molecular pathway for thyroid hormone biosynthesis is disrupted (2). Historically, $75-85 \%$ of $\mathrm{CH}$ cases have been attributed to TD with the remainder occurring due to dyshormonogenesis. However, studies undertaken more recently using lower screening TSH diagnostic cut-offs have reported a doubling in the incidence of $\mathrm{CH}$ largely due to increased diagnosis of cases with gland in situ (GIS) (3). TD is generally considered to be a sporadic disease for which the underlying aetiology is usually not clear. Genetic causes involve genes mediating thyroid differentiation, migration and growth; however, less than 5\% TD cases are attributable to a mutation in a known TD-associated gene. In contrast, the majority of individuals with dyshormonogenesis harbour mutations in genes encoding known components of the thyroid hormone biosynthesis machinery $(2,4)$.

Central $\mathrm{CH}(\mathrm{CCH})$ occurs when defective stimulation of a normal thyroid gland by thyroidstimulating hormone (TSH) results in inadequate thyroid hormone biosynthesis. Hypothalamic or pituitary pathology causes a qualitative or quantitative deficit in TSH synthesis or secretion, and in the majority of cases, the molecular basis has remained unresolved (5). Although $\mathrm{CCH}$ most commonly manifests with normal or subnormal TSH levels despite subnormal thyroid hormone concentrations, mildly elevated serum levels of immunoreactive TSH with impaired bioactivity may be detected if the defect is predominantly hypothalamic (maximum $12.9 \mathrm{mIU} / \mathrm{L}$ in one study), with the potential for misdiagnosis as subclinical or mild primary hypothyroidism (6). Although assumed to be rare, $\mathrm{CCH}$ may be more common than previously appreciated with an incidence of up to 1:16 400 to $1: 21000$ in the Netherlands $(7,8)$. Most individuals with $\mathrm{CCH}$ exhibit additional pituitary hormone deficits, but isolated TSH deficiency occurs with an estimated incidence of around 1:65 000, often as a result of defects in genes controlling the TSH biosynthetic pathway $(5,9)$.

Adequate circulating thyroid hormone levels are a prerequisite for normal childhood growth and neurodevelopment, therefore, prompt detection and treatment of $\mathrm{CH}$ is an important public health concern. Although most industrialized countries operate neonatal screening programmes for $\mathrm{CH}$, most employ a primary TSH-based methodology which will detect primary $\mathrm{CH}$ but not $\mathrm{CCH}$. This review will focus on primary $\mathrm{CH}$ and isolated $\mathrm{CCH}$, incorporating discussion of genetic aetiological advances as well as summarizing recent epidemiological data and clinical diagnostic challenges for these conditions.

\section{Primary CH}

\section{Epidemiology}

Prior to the development of $\mathrm{CH}$ screening, the incidence of primary $\mathrm{CH}$ was estimated at 1:7000 $(10,11)$; however, once screening was introduced, the actual incidence was found to be almost double these original estimates at 1:3000-4000 (12). Over the last two decades, the detected incidence of $\mathrm{CH}$ has doubled again, largely due to increased diagnosis of cases with gland-in-situ (GIS), with a lesser contribution from thyroid ectopy or cases with a structurally abnormal gland in situ. The number of children with athyreosis seems unchanged (3).

The contributing factors underlying this altered incidence are complex $(3,13,14,15,16)$. Some argue that the increase in $\mathrm{CH}$ cases is due to a generalized lowering of newborn screening cutpoints that has arisen with assay changes and reports of missed cases of $\mathrm{CH}$. However, the prevalence of $\mathrm{CH}$ has also increased in programmes where the cutpoints have not been altered $(14,15)$. Additional influences include changes in ethnicity and demographics of the populations screened $(14,16,17)$ and dietary iodine insufficiency may also be contributing to the number of children with slightly higher TSH concentrations (18). The extent to which iodine deficiency interacts with variants in the genes mediating thyroidal iodine metabolism to provoke $\mathrm{CH}$ remains unclear.

In addition to the overall increased incidence of $\mathrm{CH}$, there is also an increase in the proportion of children with transient hypothyroidism. These children meet the biochemical criteria for $\mathrm{CH}$ treatment in infancy but no longer require levothyroxine when retested around 3 years of age. Transient $\mathrm{CH}$ may reflect mild dyshormonogenesis with failure of adequate thyroxine (T4) production to meet the increased requirements in the first months of life, but sufficient hormone biosynthesis for later childhood years. The risk of subclinical or overt hypothyroidism in later life and potential for hypothyroidism in pregnancy when there is a further increased physiological demand for levothyroxine has not yet been fully evaluated in such patients. 

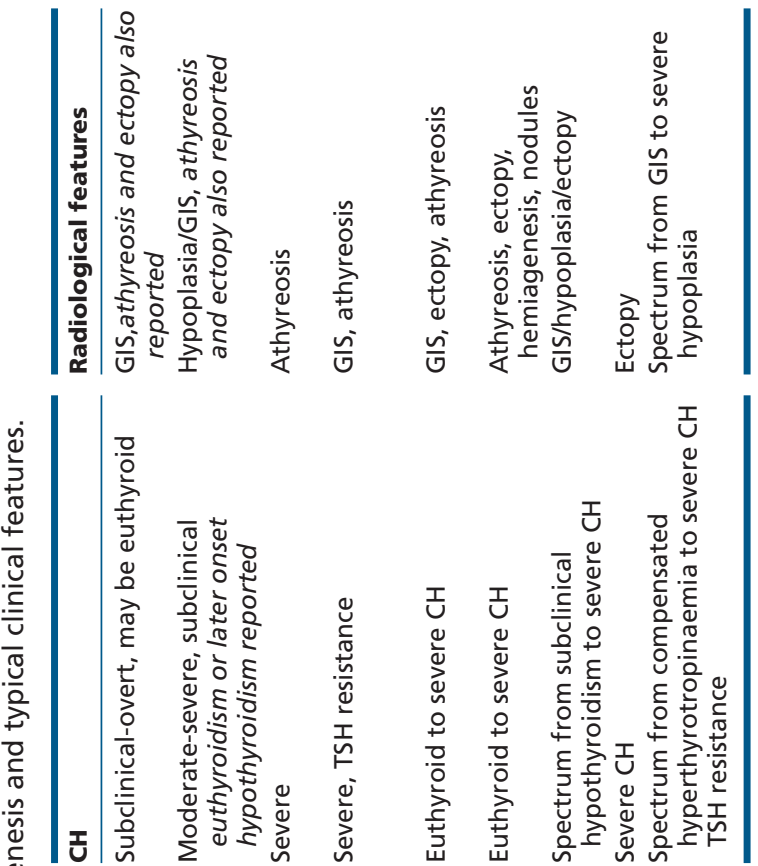

\section{Genetic advances in primary $\mathrm{CH}$}

\section{Monogenic causes of TD}

In more than 95\% cases, the aetiology for TD cannot be identified; however, genetic ascertainment in $\mathrm{CH}$ cases has established five key monogenic causes of TD: lossof-function mutations in TSHR (TSH receptor), NKX21 (NK2 homeobox 1, previously known as TTF1), PAX8 (Paired box 8), FOXE1 (Forkhead box E1, previously known as TTF2) and most recently, GLIS3 (GLIS family zinc finger 3). PAX8, NKX2-1 and FOXE1, together with HHEX (haematopoetically expressed homeobox) encode an indispensable quartet of transcription factors which define early thyroid development in both humans and mice. Although these transcription factors act in concert to mediate organogenesis only in epithelial thyroid follicular cells, they also have individual developmental roles in extrathyroidal tissues (19). TSHR is the thyroidal G-protein-coupled receptor for TSH (20), and GLIS3 plays a role in both transcriptional repression and activation in multiple organs from early on in embryogenesis (21).

\section{Key transcription factor mutations in TD}

Monogenic loss-of-function mutations in NKX2-1, PAX8 and FOXE1 are rare but well-established causes of TD, and deficiencies in these genes underlie distinct syndromes reflecting their additional, extrathyroidal expression patterns (Table 1), however, expressivity and phenotypic penetrance may be highly variable, even within the same family $(1,22)$.

\section{$N K X 2-1$}

Heterozygous loss-of-function NKX2-1 mutations are the most frequent transcription factor mutation in $\mathrm{CH}$. NKX2-1 plays a major role in the regulation of key genes involved in thyroid differentiation (including TSHR, TG and TPO), and Nkx2-1-null mice also exhibit a visible embryonic thyroid bud which disappears around E10.5-11, suggesting that $N k \times 2-1$ may play a role in thyroid precursor cell survival $(23,24)$. Additionally, $N k x 2-1$ is required for maintenance of the normal architecture and function of differentiated thyroid (25) and has extrathyroidal roles, being required for pulmonary surfactant production and contributing to development of the ventral forebrain and hypothalamic neurons. Consequently, NKX2-1 mutations result in cerebral and pulmonary phenotypes in addition 
to thyroid dysfunction, with a complete triad constituting 'brain-lung-thyroid' syndrome. Figure $1 \mathrm{~A}$ summarizes the distribution of phenotypes in cases with NKX2-1 mutations. Neurological manifestations typically include a benign hereditary chorea but may comprise hypotonia, ataxia and developmental delay. Hypothyroidism is usually mild or subclinical with normal thyroid morphology although gland hypoplasia, haemiagenesis or athyreosis are also described (26). Pulmonary compromise includes infant respiratory distress syndrome (IRDS), recurrent infections and airways hypersensitivity and carries an associated mortality of up to $16 \%(22,27)$.

NKX2-1 mutations may exhibit autosomal dominant inheritance with variable expressivity and penetrance, but frequently occur de novo, which, if confirmed, may reassure parents that the risk to future offspring is minimal (22). Most mutations are thought to result in a phenotype due to haploinsufficiency, but a minority of variants with dominant negative effects have also been described (22, 28). Deletions involving NKX2-1 are common and should be specifically excluded in brain-lung-thyroid syndrome; moreover, deletions proximal to NKX2-1 have also been implicated, suggesting the presence of an upstream enhancer in this region (27).

\section{PAX8}

PAX8 is also crucial for expression of the genes involved in thyroid differentiation and hormone biosynthesis including $T G$, TPO and SLC5A5 $(19,29,30)$. Additionally, the disappearance of the thyroid cell precursors in Pax8-null mice at around E11-11.5 attests to a likely role for PAX8 in thyroid precursor cell survival (31). Indeed, Pax8 also controls thyroid cell survival in adults and is involved in the maintenance of adult thyroid follicular cell differentiation (32).

Twenty-nine heterozygous loss-of-function PAX8 mutations defined as 'disease causing' are reported in HGMD (Human Gene Mutation Database (HGMD) Professional 2018.1), the majority comprising substitutions affecting the DNA-binding domain. Inheritance is autosomal dominant with variable expressivity and penetrance and both dominant negative effects and haploinsufficiency may mediate disease phenotype $(33,34)$. Affected patients predominantly exhibit thyroid hypoplasia; however, GIS, ectopy and athyreosis may also occur (Fig. 1B) (35). Despite $\mathrm{CH}$ in most affected patients, thyroid dysfunction may also be transient or subclinical and manifest in later childhood or adulthood (36). PAX8 is also expressed in the nephrogenic mesenchyme and rarely, mutations have been associated with urogenital tract abnormalities (36).

\section{A Organ Involvement in patients with NKX2-1 Mutations}

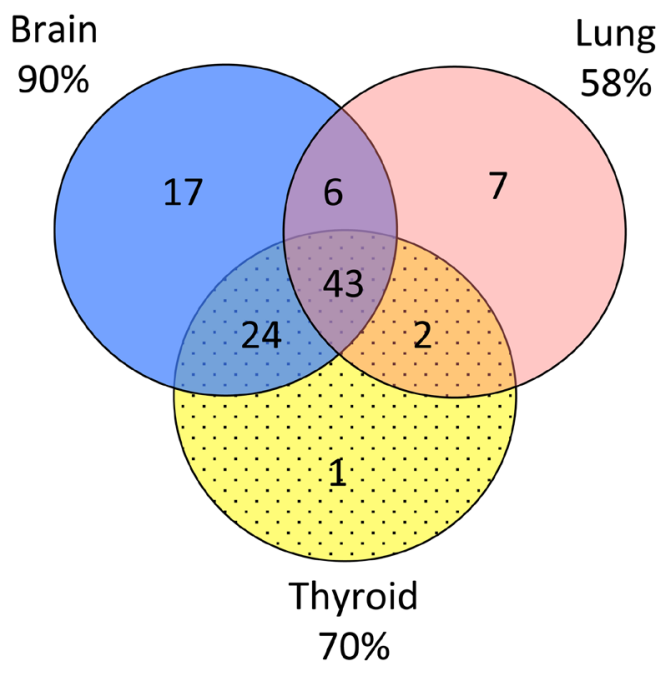

\section{B Thyroid Morphology associated with PAX8 Mutations}

\section{Hemiagenesis}

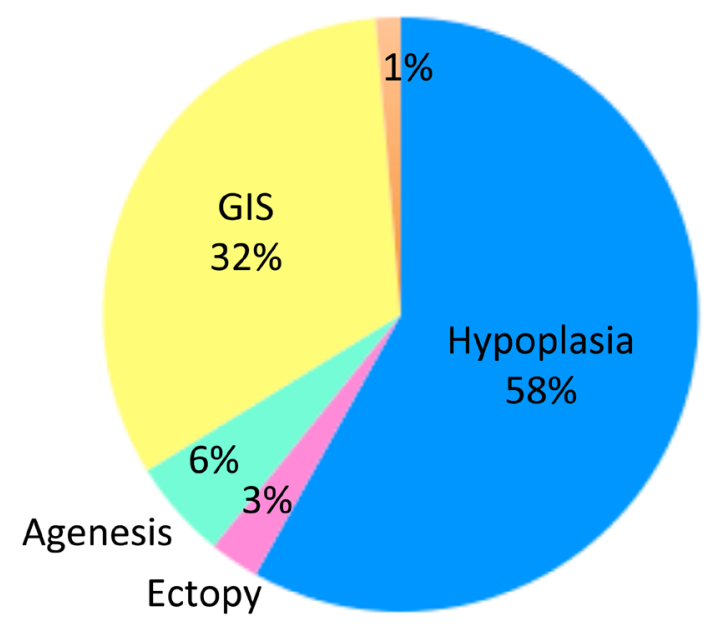

\section{Figure 1}

(B) Reported thyroid morphologies in the 84 individuals with missense or small indel mutations in PAX 8 categorized as 'disease-causing' by HGMD. Numbers refer to the percentage of cases in each morphological category. (A) Venn diagram summarizing neurological, pulmonary and thyroid phenotypes in 180 individuals harbouring missense or small indel mutations in NKX2-1 categorized as 'disease-causing' by HGMD. Individuals were only included if information was available regarding all three phenotypes (including the absence of phenotype). Numbers refer to percentages of the cohort. 


\section{FOXE1}

FOXE1 is a transcription factor in the forkhead domain family, which is expressed in the developing oropharynx, oesophagus, choanae and hair follicles. Foxe1-null mice develop a rudimentary thyroid bud, which either remains in an ectopic site at the base of the tongue, or disappears, supporting a role for FOXE1 in thyroid migration as well as differentiation and survival of the developing thyroid gland. Additionally, FOXE1 has a role in maintenance of the mature, differentiated thyroid, for example enabling expression of genes involved in thyroid hormone biosynthesis $(37,38)$.

At least seven biallelic $\mathrm{CH}$-associated FOXE1 point mutations have now been reported and affected patients typically exhibit athyreosis or severe thyroid hypoplasia, in association with cleft palate and spiky hair (BamforthLazarus syndrome). Choanal atresia and bifid epiglottis may also occur, reflecting the expression of FOXE1 in epiglottis, palate, oesophagus, definitive choanae and hair follicles (39). Inheritance of FOXE1 mutations is autosomal recessive and all described mutations cluster in the forkhead DNA-binding domain. All except one impair both DNA binding and transcriptional activity of FOXE1 resulting in loss of function. A single gain-of-function mutation in the same region results in enhanced activity of $T G$ and TPO promoters, but the associated clinical phenotype is indistinguishable from that associated with loss-of-function mutations (40).

\section{GLIS3}

GLIS3 is a member of the GLI-similar 1-3 (GLIS1-3) subfamily of Krüppel-like zinc finger protein transcription factors, which play a key regulatory role in embryogenesis. GLIS3 may act as a transcriptional activator or repressor and is particularly important in the regulation of pancreatic $\beta$ cell generation and maturation, insulin gene expression, thyroid hormone biosynthesis, spermatogenesis and the maintenance of normal kidney function. Biallelic lossof-function mutations in GLIS3 have now been described in children from 14 different families and are robustly associated with $\mathrm{CH}$ in all but one case as part of a variably penetrant multisystem phenotype consistently including permanent neonatal diabetes (Table 1) (21). Inheritance is autosomal recessive. Thyroid morphology ranges from apparently normal to hypoplasia or gland athyreosis; however, histology from an ultrasonographically normal gland demonstrated abnormal architecture with a paucity of colloid and extensive fibrosis. Significant TSH resistance frequently compounds management of children harbouring GLIS3 mutations, perhaps explained by its actions downstream of TSH and the TSHR, since GLIS3 is indispensable for TSH/TSHR-mediated proliferation of thyroid follicular cells and biosynthesis of thyroid hormone $(21,41)$. Additionally, in some cases, elevated TSH and thyroglobulin levels appear to be resistant to treatment with conventional doses of levothyroxine therapy despite normalization of free T4 (21).

\section{TSHR}

TSHR mutations result in TSH resistance, for which the associated phenotype is dependent on both the deleteriousness of the mutation, and the number of mutated TSHR alleles, since inheritance may be either dominant or recessive (1). Complete TSH resistance manifests as severe biochemical $\mathrm{CH}$ with orthotopic gland hypoplasia, however, at the milder end of the spectrum, isolated hyperthyrotropinaemia may be associated with preserved thyroid hormone biosynthesis from a normalsized thyroid gland. Early thyroid development, and thyroglobulin (TG) synthesis at the onset of folliculogenesis is TSH independent. Therefore, even severe TSHR mutations cause only apparent athyreosis, i.e. marked thyroid hypoplasia which is undetectable on imaging but associated with a measurable serum thyroglobulin (TG) confirming the presence of some residual thyroid tissue (20). TSH plays a role in thyroid growth from the third trimester and subsequently stimulates thyroid hormone synthesis and release.

Around 100 likely inactivating TSHR mutations have been reported, the incidence of which depends on the clinical characteristics and ethnicity of the $\mathrm{CH}$ population screened. Heterozygous TSHR mutations causing partial TSH resistance, are most frequently described, with incidences of 11-29\% in Italian studies of non-autoimmune hyperthyrotropinaemia (42). The contribution of TSHR mutations to orthotopic thyroid hypoplasia is more difficult to estimate, since most studies involving such cases include additional thyroid morphologies, but in a consanguineous Pakistani and Turkish cohort, TSHR mutations were the most common genetic cause of non-goitrous $\mathrm{CH}$, affecting 5\% families (43). Founder mutations also operate, e.g. TSHR p.R450H in individuals from East Asia (1).

TSHR mutations occur throughout the protein, with nonsense and frameshift mutations generally decreasing levels of TSHR expressed at the plasma membrane. Most point mutations result in decreased signal transduction 
by the receptor, but may also affect ligand binding, depending on their location. A dominant-negative mechanism may contribute to phenotypic severity in some cases, e.g. in association with TSHR p.C41S, which entraps WT receptor intracellularly by forming oligomers (42).

In complete TSH resistance with subnormal FT4 levels, levothyroxine replacement is unequivocally required but the need for treatment in partial TSH resistance remains controversial since, in this context, elevated TSH levels are sufficient to maintain normal circulating thyroid hormone concentrations (42). Additionally, exogenous T3 administration elicits normal fractional changes in serum TSH and peripheral biomarkers of thyroid hormone action, signifying normal sensitivity of pituitary thyrotrophs and peripheral tissues to thyroid hormone $(44,45)$. The mechanisms permitting continued secretion of high levels of TSH with T4 levels within the normal range are unclear, but this biochemical signature may represent a resetting of the threshold for TSH suppression by circulating thyroid hormones. Accordingly, supraphysiological FT4 concentrations are required to achieve a TSH level in the normal range $(44,45)$. The molecular mechanisms supporting an altered TSH set point have not yet been elucidated and may include altered expression of genes involved in set point regulation at different points in the hypothalamic-pituitary-thyroid axis or genes mediating thyroid hormone metabolism (20).

Since peripheral sensitivity to thyroid hormone is preserved, the doses of levothyroxine required to normalize TSH in partial TSH resistance may provoke thyrotoxic symptoms, and anecdotal reports of normal growth, development and pituitary size in untreated cases despite chronically raised TSH support the argument that levothyroxine treatment may be unnecessary $(44,45)$. Two recent studies from Israel and Italy have addressed this question in patients with TSHR mutations; in the Italian cohort, the effect of thyroid hormone replacement on developmental parameters and biomarkers of thyroid hormone action was also assessed. Both studies concluded that biochemical features associated with heterozygous TSHR mutations (elevated TSH, normal circulating thyroid hormone concentration) were generally stable, representing a compensated state which may not require thyroid hormone replacement. However, in patients with either heterozygous mutations and additional risk factors for thyroid dysfunction, or biallelic mutations, compensation of thyroid hormone biosynthesis by elevated TSH levels may be incomplete and progress, resulting in deteriorating thyroid hormone levels and a need for levothyroxine treatment $(46,47)$. Larger studies, including monoallelic TSHR mutations associated with a broader spectrum of TSH levels, are still required to guide management definitively. Meanwhile, levothyroxine replacement therapy in partial TSH resistance should be considered on a case by case basis and is not indicated for the treatment of elevated TSH alone although in some affected individuals, signs and symptoms of hypothyroidism or declining thyroid hormone levels may justify intervention.

\section{Additional genes associated with TD}

\section{$N K X 2-5$}

NKX2-5 belongs to the NK-2 family of homeodomaincontaining transcription factors and was initially an attractive candidate gene for TD, having been shown to play a role in murine thyroid development. Nkx2-5 is expressed during early murine thyroid morphogenesis and murine $N k \times 2-5$-null embryos exhibit thyroid bud hypoplasia. However, despite an initial report of four patients with heterozygous loss-of-function NKX2-5 mutations and thyroid ectopy or athyreosis, the role of NKX2-5 in TD remains ambiguous. Inheritance in these families was autosomal dominant but mutation penetrance was highly variable (carrier parents frequently had normal thyroid morphology and biochemistry) and pathogenic mutations may also occur either in healthy populations (p.R25C, MAF $>1 \%$ ) or in association with isolated congenital heart disease $(48,49)$. Although NKX2-5 variants may contribute to TD risk, other factors/ genes are likely to play a significant role modulating penetrance and expressivity.

\section{JAG1}

Jagged1 (JAG1) is a Notch receptor ligand expressed in thyroid, which may play a role in thyroid specification in zebrafish, as well as in differentiation and maintenance of thyroid precursor cells (50). JAG1 plays a role in zebrafish thyroid development and variably penetrant, human heterozygous loss-of-function JAG1 mutations are associated with Alagille syndrome in which congenital heart disease (CHD) associates with variable hepatic, eye and skeletal defects together with dysmorphic facies. Evaluation of thyroid function in 21 cases with Alagille syndrome revealed mild, non-autoimmune hypothyroidism in six individuals. Additionally, $4 \%$ cases 
in a $\mathrm{CH}$ cohort without associated Alagille syndrome harboured heterozygous JAG1 mutations (with associated CHD in two patients). Rare JAG1 variants have also been detected in an unrelated $\mathrm{CH}$ cohort substantiating the notion that JAG1 may contribute to the pathogenesis of $\mathrm{CH}(51,52)$.

\section{CDCA8 (BOREALIN)}

CDCA8 is a member of the chromosomal passenger complex with roles in the processes of chromosome segregation and cytokinesis. It is expressed in human thyroid tissue during embryonic development and is the most recently identified genetic cause of TD with monoand biallelic loss-of-function mutations reported in three unrelated families. A homozygous CDCA8 mutation (p.S148F) in two siblings was associated either with $\mathrm{CH}$ and thyroid ectopy or euthyroidism with thyroid hemiagenesis. In two more families, heterozygous CDCA8 mutations were associated with $\mathrm{CH}$ and either thyroid ectopy or athyreosis. Euthyroid heterozygous parents exhibited variable thyroid structural abnormalities (asymmetry, nodules) and one developed papillary thyroid cancer. Expression of mutant CDCA8 in a thyroid cell line resulted in altered cellular migration and adhesion by decreasing the expression of genes implicated in focal adhesion (53).

\section{Netrin 1 (NTN1)}

The close proximity of the developing thyroid to cardiac mesenchyme and vasculature, and the increased frequency of cardiovascular malformations in patients with TD, has led to the suggestion that non-cell autonomous mesenchyme-derived factors may play a role in thyroid development. Zebrafish have proved a useful tool in investigating the mechanisms involved and Netrin 1-deficient zebrafish embryos demonstrate defective aortic arch artery formation in addition to abnormal thyroid morphogenesis. Since ntn1a, the zebrafish paralog of human NTN1, is expressed in pharyngeal arch mesenchyme but not in thyroid tissue, it is likely that the thyroid fails to develop due to lack of guidance cues from dysplastic vasculature. A single patient with VSD and thyroid ectopy was reported in whom a heterozygous deletion involving part of NTN1 was detected in addition to a 47 , XYY karyotype and an atypical 22q11 deletion. However, the extent to which NTN1 mutations contribute to shared thyroid and cardiac congenital defects in the population remains unclear (54).

\section{Syndromes which may be associated with $\mathbf{C H}$}

Risk of $\mathrm{CH}$ may be increased in the context of several syndromes with an underlying genetic basis and predominantly extrathyroidal-associated abnormalities. Candidate genes involved include SALL1 (Townes-Brocks syndrome), TBX1 (di George syndrome), URB1 (JohansonBlizzard syndrome), DYRK1A (Trisomy 21), ELN (WilliamsBeuren syndrome), KMT2D/MLL2, KDM6A (Kabuki syndrome) and KAT6B (Ohdo syndrome, Genitopatelar syndrome) (4). The underlying mechanism for $\mathrm{CH}$ in these conditions is generally unclear, and the genes involved usually demonstrate ubiquitous expression, including expression in thyroid. TBX1 is a non-cell autonomous factor likely derived from cardiac mesenchyme, required for thyroid development (38).

\section{Genetic causes of dyshormonogenesis}

Unlike TD, the majority of dyshormonogenesis has an identifiable genetic basis. Thyroid hormone biosynthesis at the apical surface of polarized thyroid follicular cells requires an intact synthesis pathway comprising transporter molecules, enzymes, thyroglobulin (TG) and adequate iodide substrate (Fig. 2). Genetic causes of dyshormonogenesis comprise loss-of-function mutations in genes encoding components of the thyroid hormone biosynthetic machinery resulting in inadequate thyroid hormone synthesis with or without compensatory goitre. Mutations may involve TG, TPO, SLC26A4 (Pendrin), SLC5A5 (NIS), DUOX2, DUOXA2 or IYD. Inheritance patterns and associated features are dependent on the site of the synthesis defect and summarized in Table $2(1,2)$.

The frequencies of dyshormonogenesis-associated mutations are heavily influenced by ethnicity, including the presence of founder mutations, and selection criteria for the study population. $T G$ mutations are a common cause of dyshormonogenesis with an estimated frequency of at least 1:100 000 births (55). TPO defects represent the commonest cause of total iodide organification defect (TIOD, 56), and frequently underlie dyshormonogenesis in European and Pakistani cases (57) but may occur less frequently in East Asian individuals $(58,59)$. DUOX2 mutations are now frequently reported, especially in East Asian individuals, with a monoallelic frequency of up to $1: 13501$ in Korean cases $(58,59)$ and also account for $37 \% \mathrm{CH}$ due to partial iodide organification defect (PIOD) in an Italian series (60). Some pathogenic DUOX2 
mutations have a minor allele frequency of $\geq 1 \%$ in certain populations (e.g. p.Q570L in South Asians) suggesting that they may be an even more frequent contributor to $\mathrm{CH}$ than previously recognized (60). Mutations in SLC5A5, and IYD seem rare, with IYD mutations only identified in five families (55) and DUOXA2 mutations are also uncommon although probably occur most frequently in East Asian cases (59). Although Pendred syndrome occurs more frequently in the general population (estimated incidence $7.5-10$ per 100000$), \mathrm{CH}$ is a rare association such that Pendrin mutations account for less than $5 \%$ of $\mathrm{CH}(2,61,62)$.

\section{Clinical phenotypes in dyshormonogenesis}

Biochemical and radiological hallmarks of specific, genetically ascertained dyshormonogeneses are summarized in Table 2; however, evidence increasingly supports a broader phenotypic range in most dyshormonogenesis subtypes than initially appreciated. This is particularly well documented for $\mathrm{CH}$ associated with mutations in DUOX2, which were first reported only in 2002. DUOX2 is a thyroidal NADPH oxidase, which generates the thyroidal $\mathrm{H}_{2} \mathrm{O}_{2}$ required by TPO as the final electron acceptor during both iodination of thyroglobulin and coupling of mono and diiodotyrosine. It is contiguous with DUOX1, (an additional NADPH oxidase) on the long arm of chromosome 15, with the DUOXA maturation factor genes occupying the DUOX intergenic region. DUOX2 is thought to be the dominant isoenzyme in thyroid hormonogenesis, being expressed at higher levels in thyroid than DUOX1 and consistent with this, DUOX2 but not DUOX1 mutations are a recognized monogenic cause of $\mathrm{CH}$. Additionally, DUOX1-null mice do not exhibit hypothyroidism (63).

To date, approximately 100 different DUOX2 mutations have been reported, including missense, stop codon, splice-site and in-frame deletion mutations. However, only around 50\% missense mutations have been functionally characterized, leading to some ambiguity about the number of these which are truly pathogenic. Indeed, functional evaluation has confirmed that some likely benign polymorphisms have been misclassified as disease causing (60). Functional characterization of DUOX2 mutations was initially hampered by failure

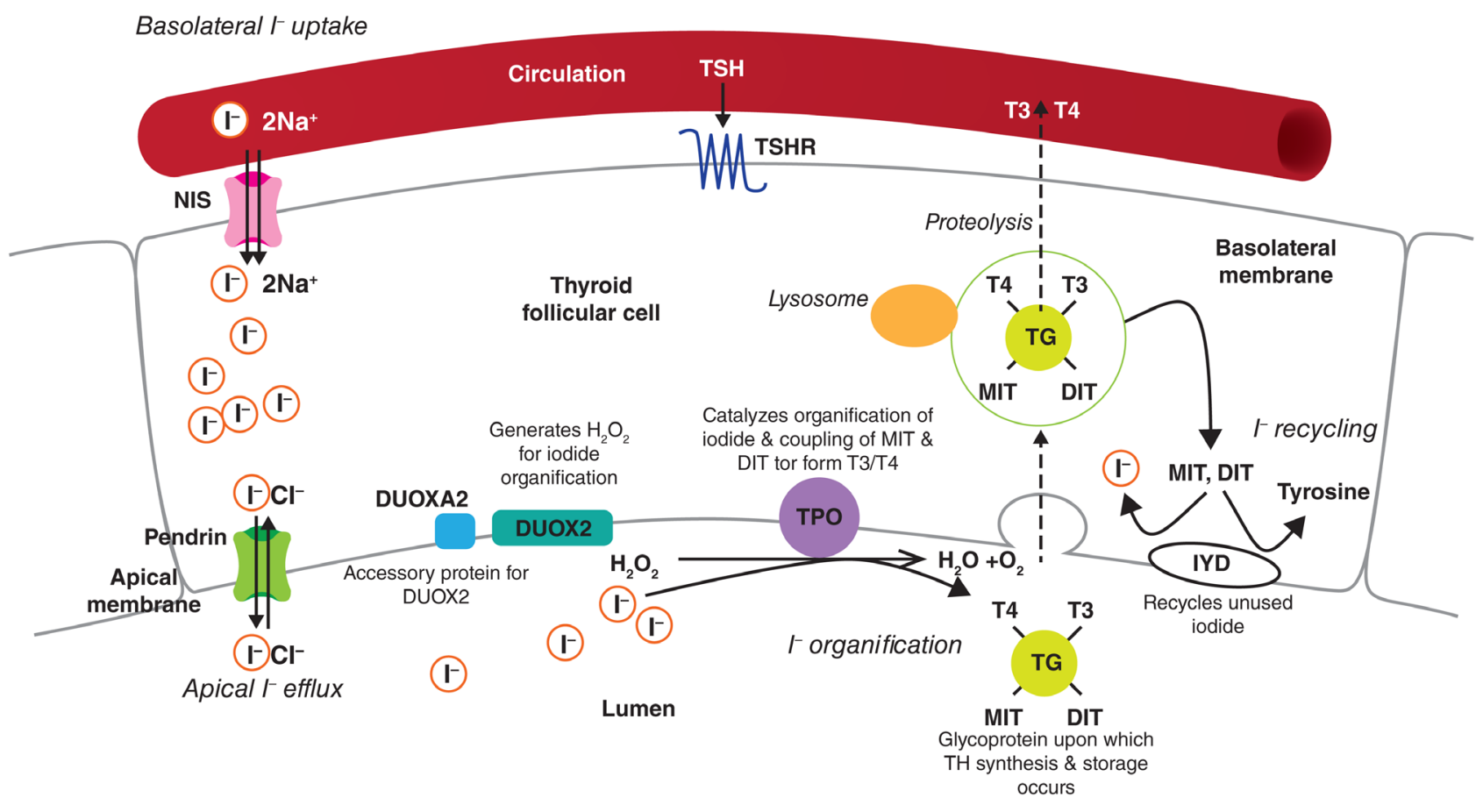

Figure 2

Schematic illustrating thyroid hormone biosynthesis in the thyroid follicular cell, highlighting the position and function of the molecules involved. Mutations in any of these proteins may result in dyshormonogenesis. 
Table 2 A summary of the genetic defects implicated in $\mathrm{CH}$ with dyshormonogenesis and typical clinical features.

\begin{tabular}{|c|c|c|c|c|c|}
\hline Gene & Function & $M / B$ & Additional clinical features & CH & Radiological features \\
\hline TG & $\begin{array}{l}\text { Glycoprotein upon } \\
\text { which thyroid } \\
\text { hormones are } \\
\text { synthesized and stored }\end{array}$ & B & $\begin{array}{l}\text { Fetal goiter (rare) } \\
\text { Inappropriately low TG when TSH } \\
\text { is elevated. }\end{array}$ & $\begin{array}{l}\text { Spectrum from } \\
\text { euthyroidism to severe } \\
\text { CH }\end{array}$ & $\begin{array}{l}\text { GIS/Goitre } \\
\text { Normal or impaired } \\
\text { organification of } \\
\text { iodide }\end{array}$ \\
\hline TPO & $\begin{array}{l}\text { Organification of } \\
\text { iodide, catalysis of } \\
\text { coupling reactions } \\
\text { (final step in TH } \\
\text { synthesis) }\end{array}$ & $B^{*}$ & Fetal goitre (rare) & $\begin{array}{l}\text { Severe } \mathrm{CH} \\
\text { Sometimes mild } \mathrm{CH} \text { with } \\
\text { monoallelic variants }\end{array}$ & $\begin{array}{l}\text { GIS/Goitre } \\
\text { TIOD, rarely PIOD }\end{array}$ \\
\hline$D \cup O X 2$ & $\begin{array}{l}\mathrm{H}_{2} \mathrm{O}_{2} \text { production, } \\
\text { required for iodide } \\
\text { organification }\end{array}$ & $\mathrm{M} / \mathrm{B}$ & $\begin{array}{l}\text { Borderline blood spot TSH but } \\
\text { subnormal venous T4 and } \\
\text { significantly elevated TSH at } \\
\text { confirmatory testing }\end{array}$ & $\begin{array}{l}\text { Usually mild-moderate or } \\
\text { transient } \mathrm{CH}\end{array}$ & $\begin{array}{l}\text { GIS/Goitre } \\
\text { PIOD }\end{array}$ \\
\hline DUOXA2 & $\begin{array}{l}\text { Membrane expression } \\
\text { and function of } \\
\text { DUOX2 }\end{array}$ & $\mathrm{M} / \mathrm{B}$ & Transient or permanent & Mild/transient $\mathrm{CH}$ & $\begin{array}{l}\text { GIS/Goitre } \\
\text { PIOD }\end{array}$ \\
\hline Pendrin & Apical iodide efflux & M & $\begin{array}{l}\text { Sensorineural hearing loss with } \\
\text { EVA }\end{array}$ & $\begin{array}{l}\text { Euthyroid/mild } \\
\text { hypothyroidism }\end{array}$ & $\begin{array}{l}\text { GIS/Goitre } \\
\text { PIOD }\end{array}$ \\
\hline NIS & $\begin{array}{l}\text { Basolateral iodide } \\
\text { uptake }\end{array}$ & M & $\begin{array}{l}\text { May present later in childhood } \\
\text { resulting in neurodevelopmental } \\
\text { delay }\end{array}$ & $\begin{array}{l}\text { Spectrum from } \\
\text { euthyroidism to severe } \\
\mathrm{CH}\end{array}$ & $\begin{array}{l}\text { GIS/Goitre } \\
\text { Severely impaired } \\
\text { thyroid }{ }^{123} \mid / T c \\
\text { uptake }\end{array}$ \\
\hline$I Y D$ & $\begin{array}{l}\text { Recycling of unused } \\
\text { iodide moieties (MIT } \\
\text { and DIT) }\end{array}$ & $\mathrm{M} / \mathrm{B}$ & $\begin{array}{l}\text { Raised urinary MIT and DIT } \\
\text { May present later in childhood } \\
\text { resulting in neurodevelopmental } \\
\text { delay }\end{array}$ & $\begin{array}{l}\text { Spectrum from } \\
\text { euthyroidism to severe } \\
\mathrm{CH} \text {; later onset } \\
\text { hypothyroidism } \\
\text { reported }\end{array}$ & $\begin{array}{l}\text { Goitre } \\
\text { Normal } \\
\text { organification of } \\
\text { iodide }\end{array}$ \\
\hline
\end{tabular}

*Occasional monoallelic cases reported.

B, bilallelic; EVA, enlarged vestibular aqueduct; GIS, thyroid gland in situ; M, monoallelic; PIOD, partial iodide organification defect; TIOD, total iodide organification defect.

to achieve plasma membrane expression of DUOX2 in heterologous cell systems, however, identification and coexpression of the DUOXA2 maturation factor for DUOX2 enables correct translocation of DUOX2 from the ER and has permitted such evaluation (64). The mechanisms and degree to which pathogenic mutations exhibit impaired $\mathrm{H}_{2} \mathrm{O}_{2}$ generation are variable, including both complete and partial deficits in $\mathrm{H}_{2} \mathrm{O}_{2}$ generation. Truncating mutations are usually predicted to result in impaired enzyme activity due to disruption of the C-terminal NADPH oxidase domain. Cell membrane expression was evaluated for six missense mutations, which significantly impair DUOX2 function. All exhibited complete or partial trafficking defects from the endoplasmic reticulum to the cell surface and decreased plasma membrane expression $(65,66)$, with preserved or absent intrinsic $\mathrm{H}_{2} \mathrm{O}_{2}$-generating activity $(66,67)$.

Both monoallelic and biallelic DUOX2 mutations have been described, and heterozygous mutations are thought to confer a phenotype due to haploinsufficiency since evidence for dominant negative activity is currently lacking (66). Initially, biallelic DUOX2 mutations were thought to result in permanent $\mathrm{CH}$, and monoallelic mutations to cause transient $\mathrm{CH}$ (68). However, subsequent studies have shown almost $40 \%$ discordancy with this observation; additionally, penetrance is highly variable and biallelic truncating mutations may be associated with both mild transient and severe permanent $\mathrm{CH}$ (69). Although sometimes associated with goitrous dyshormonogenesis, DUOX2 mutations may also cause a resistance to thyrotropin phenotype (70). Additionally, next-generation sequencing recently identified frequent DUOX2 $\mathrm{NH}_{2}$-terminal mutations in cases with thyroid ectopy, raising the possibility of a role for DUOX2 in thyroid development, for which the mechanism and putative $\mathrm{H}_{2} \mathrm{O}_{2}$ dependency remain unclear (71).

It has been suggested that variants in other $\mathrm{H}_{2} \mathrm{O}_{2}$ synthesizing enzymes capable of compensating for DUOX2 deficiency, e.g. DUOX1, may modulate $\mathrm{CH}$ severity (2) and the first cases with likely complete DUOX isoenzyme deficiency were recently reported; although detailed genotype-phenotype segregation studies were not performed, these cases exhibited unusually severe $\mathrm{CH}$ consistent with a compensatory role for DUOX1 (72). In contrast, mice homozygous for a DUOX2 point mutation alone, exhibit severe hypothyroidism, suggesting that 
DUOX1 expression is unable to compensate for the DUOX2 defect in the murine model (73). Evaluation of Italian cases harbouring DUOX2 mutations demonstrated characteristics associated biochemistry including significantly elevated confirmatory TSH and subnormal venous FT4 measurements despite borderline neonatal screening TSH, raising the possibility that cases with DUOX2 mutations could be missed on neonatal screening (60). Clinical and functional data for cases with mutations in DUOXA2, the accessory protein for DUOX2, is sparse, but most cases appear to have mild or transient $\mathrm{CH}$ and loss of function may be associated with either normal protein expression or decreased expression levels of unstable DUOXA2 $(74,75)$.

Thyroid dysfunction associated with NIS or TG mutations can range from severe $\mathrm{CH}$ to euthyroid goitre, especially if dietary iodine content is high. TPO mutations usually cause severe $\mathrm{CH}$ although milder cases with PIOD have been described, sometimes due to monoallelic defects (55) and both TG and TPO mutations are rarely associated with foetal goitre. Homozygous IYD mutation carriers generally exhibit goitrous congenital or childhood-onset hypothyroidism, and one heterozygote has also been described with hypothyroidism and goitre $(55,76)$. IYD, NIS and DUOX2 mutations may all present late, following normal neonatal screening TSH results, resulting in neurodevelopmental delay if diagnosis of infantile hypothyroidism is delayed $(2,60,76,77)$.

\section{Evidence for an undiagnosed genetic component in TD}

Causative mutations are identified in less than 5\% of TD cases, leading to the assumption that TD is a sporadic disease. This notion is supported by a higher than $90 \%$ discordance between monozygotic twins with $\mathrm{CH}$ (78) and a strong female preponderance of TD, especially thyroid ectopy (79). Since these features are incompatible with simple Mendelian inheritance, it has been hypothesized that somatic mutations restricted to the thyroid or epigenetic events may be implicated.

However, other lines of investigation support a more significant aetiological role for germline mutations in TD than currently diagnosed. Two percent of TD cases in a French National Survey of $\mathrm{CH}$ have an affected relative, which is 15 -fold greater than predicted by chance alone. Moreover, thyroid developmental abnormalities occur more commonly in euthyroid first-degree relatives of $\mathrm{CH}$ cases than in controls $(80,81)$ and the incidence of extrathyroidal developmental malformations is also increased in patients with $\mathrm{CH}$. Additionally, $\mathrm{CH}$ occurs more frequently in consanguineous or less genetically diverse populations $(82,83)$.

\section{Alternative genetic aetiologies in TD and dyshormonogenetic $\mathrm{CH}$}

Recent studies have sought alternative genetic aetiologies for $\mathrm{CH}$, some of which have attempted to reconcile the apparent sporadic occurrence of TD with the data supporting an aetiological role for genetic factors. Potential mechanisms consistent with these observations include two hits, where a germline predisposing mutation occurs in association with an additional genetic or epigenetic alteration within the thyroid tissue or surrounding structures (84). However, in the only study to investigate this, the gene expression pattern was different in ectopic thyroid, but this was not attributable to significant somatic methylation gene expression profile differences (85). Additionally, frequent somatic mutations were not identified in lymphocyte DNA from monozygotic twins discordant for TD (86) although somatic mosaicism for a PAX8 mutation has been reported (87). Autosomal monoallelic expression has been reported for some genes in both ectopic and eutopic thyroid (88); however, monoallelic expression of a mutant allele has only been reported for TPO in association with dyshormonogeneic $\mathrm{CH}$ (89). Recurrent copy number variants have also not been identified in $\mathrm{CH}(90)$.

Next-generation sequencing (NGS) technologies have enabled interrogation of the role of oligogenicity in $\mathrm{CH}$, which may also contribute to its apparently sporadic occurrence. An aetiological role for oligogenicity was initially supported by observations that mice with heterozygous TTF1 or PAX8 mutations are euthyroid, but strain-specific TD occurs in mice with combined partial deficiencies of TTF1 and PAX8 (91). Human studies have now confirmed a role for oligogenic inheritance in both $\mathrm{CH}$ with eutopic GIS and TD. In a particularly comprehensive study, $11 \mathrm{CH}$-associated genes were screened in more than 150 Italian patients with different $\mathrm{CH}$ subtypes, with subsequent analysis demonstrating that 23\% harboured a likely pathogenic variant in more than one gene $(52,92)$.

NGS approaches have also enabled the screening of genes classically associated with TD or dyshormonogenesis in mixed $\mathrm{CH}$ populations, demonstrating overlap of genetic aetiologies in the two morphological subgroups. Mutations in genes characteristically associated with TD 


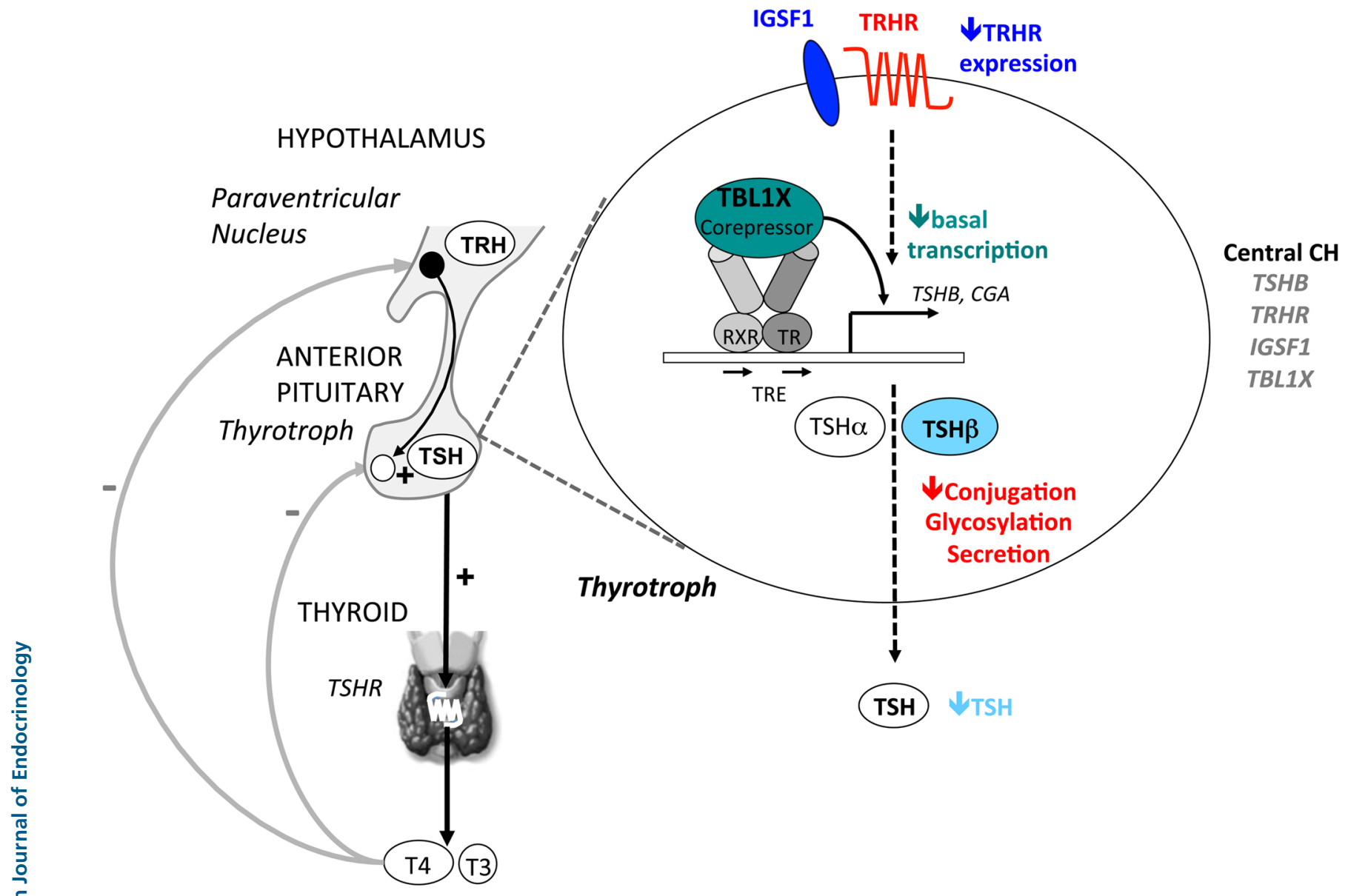

Figure 3

Diagrammatic representation of the hypothalamic-pituitary-thyroid axis with positive regulation (black) predominantly mediated by thyrotropin-releasing hormone (TRH) and negative (grey) feedback influences, predominantly mediated by thyroid hormone receptor isoforms 2 and 1 . The inset represents a pituitary thyrotroph, in which the putative sites of action of genes implicated in isolated TSH deficiency are shown. Consequences of mutations in these genes are depicted in the same colour text as the mutant protein.

(e.g. biallelic FOXE1 mutations), have been reported in association with isolated $\mathrm{CH}$ and a normal thyroid gland (52). Conversely, Pendrin mutations have been reported in TD, where secondary atrophy of the thyroid was postulated to occur due to increased oxidative stress (93).

Novel candidate genes for $\mathrm{CH}$ have also been identified by exploring mouse and zebrafish models for thyroid development (94). Recently, in murine and human pluripotent stem cell-derived endodermal precursors, expression of NKX2-1 and PAX8 alone, in response to exogenous FGF2 and BMP4 in vitro was found to be sufficient for differentiation into thyroid follicular structures capable of producing thyroid hormones when exposed to thyrotropin $(95,96)$. This stem cell technology presents an exciting system in which to validate the roles of novel candidate genes for TD in the future as well as raising the future possibility of regenerative therapy for $\mathrm{CH}$.

\section{Isolated central congenital hypothyroidism (CCH)}

The hypothalamic-pituitary-thyroid axis: positive regulation of thyroid hormone synthesis

Thyroid hormone biosynthesis is positively regulated by the actions of hypothalamic thyrotropin-releasing hormone (TRH), which stimulates TSH production from the anterior pituitary. TRH is synthesized in the paraventricular nucleus (PVN) of the hypothalamus and following maturation, reaches the thyrotrophs of the 
Table 3 Endocrine, neuroradiological and extrapituitary manifestations of mutations in genes implicated in $\mathrm{CCH}$ in humans.

\begin{tabular}{|c|c|c|c|c|c|}
\hline Gene & Inheritance & Hormone deficits & TRH test responses & MRI & Additional features \\
\hline TSHB & AR & TSH & Absent TSH response, preserved PRL response & $\mathrm{E}, \mathrm{N}$ & - \\
\hline TRHR & AR & TSH & TSH and PRL peak absent/preserved & $\mathrm{N}$ & - \\
\hline$T B L 1 X$ & $X L^{*}$ & TSH & TSH response normal & $\mathrm{N}$ & Sensorineural hearing loss \\
\hline \multicolumn{6}{|c|}{ Isolated TSH deficiency or combined pituitary hormone deficiency } \\
\hline IGSF1 & $X L^{*}$ & $\begin{array}{l}\mathrm{TSH} \pm \mathrm{PRL}, \mathrm{GH} \text { (transient) } \\
\text { Delayed pubertal } \\
\text { testosterone rise }\end{array}$ & Low normal/normal TSH response & $\mathrm{N}$ & $\begin{array}{l}\text { Macroorchidism (males) } \\
\text { Ovarian cysts (females) }\end{array}$ \\
\hline
\end{tabular}

anterior pituitary gland via the hypothalamic portal vein. It then binds the TRH receptor (TRHR), a G-protein-coupled receptor, which activates a Gq/11-dependent pathway subsequently mobilizing intracellular calcium and activating protein kinase C. TRH upregulates transcription of the TSH alpha ( $\alpha \mathrm{GSU})$ and beta subunit genes (CGA and TSHB) but also exerts important post-translational effects, facilitating conjugation of TSH alpha and beta subunits and promoting both secretion of heterodimeric TSH and its post-translational glycosylation, which is required to confer normal bioactivity (5, Fig. 3).

Genetic ascertainment in CCH due to isolated TSH deficiency has advanced over the last three decades, and a total of four genes, all with a role in TSH biosynthesis, are now implicated in its pathogenesis; thyrotropin-releasing hormone receptor (TRHR), TSH beta subunit (TSHB), immunoglobulin superfamily member 1 gene (IGSF1) and the transducin beta-like $1 \mathrm{X}$-linked gene, TBL1X $(5,97$, Table 3$)$.

\section{Genetic causes of isolated central congenital hypothyroidism}

\section{TSHB mutations}

Biallelic loss-of-function, TSHB mutations result in severe $\mathrm{CCH}$. Therefore, if diagnosis is delayed until children present clinically, the severity of hypothyroidism frequently results in neurodevelopmental impairment, the extent of which correlates with the degree of treatment delay. In contrast, developmental outcome is often improved in cases who are ascertained, diagnosed and treated from birth following genetic diagnosis in a sibling (98).

Mature TSH comprises a heterodimer of the alpha subunit ( $\alpha \mathrm{GSU}$ ) common to other glycoprotein hormone (LH, FSH, CG) family members and a beta subunit which is TSH specific (TSHB). Key structural features are required to maintain the integrity of the heterodimer including a 'seat belt' formed from the TSH beta subunit, which wraps around the long loop of the alpha subunit and forms an intra-molecular disulfide 'buckle' to stabilize the heterodimer. Additional alpha-beta subunit interactions occur around a conserved CAGYC sequence motif.

All reported missense or indel mutations either disrupt key disulphide bridges required for heterodimeric integrity, truncate the protein or disrupt the CAGYC region (Fig. 4A). The most common mutation is a single nucleotide deletion (c373delT) leading to a cysteine 125 to valine change (p.C125V) and subsequent frameshift and premature stop codon at position 134 (p.C125Vfs*10) (99), which exhibits a founder effect in some communities (98). More recently, two TSHB splice-site mutations (c162G $>$ A, c.162+5 G>A) $(100,101)$ and two TSHB deletions have been reported $(98,102)$.

$\mathrm{CCH}$ due to TSHB mutations is characterized by profound $\mathrm{CH}$ with elevated pituitary glycoprotein alpha subunit, and severely impaired TSH response to TRH administration, despite a preserved serum prolactin rise (103, Fig. 5A and B). Serum TSH levels may be undetectable with mutations (p.G49R, p.Q32*), which disrupt heterodimer formation between TSH-alpha and beta polypeptides, whereas in cases with mutations resulting in synthesis of non-bioactive heterodimeric TSH (eg p.Q69*, c.373delT), immunoreactive TSH will be detected in an immunoassay-dependent manner if epitopes recognized by the anti-TSH monoclonal antibody are preserved $(103,104)$.

\section{TRHR mutations}

Cases harbouring biallelic loss-of-function mutations in TRHR have only been reported in four kindreds (Fig. 4B). In the first two kindreds, truncating mutations completely abolished TRHR activity (compound heterozygosity for TRHR p.R17*, and an in-frame deletion of three amino 
acids (S115, I116 and T117) with one substitution (p.A118T) or homozygosity for p.R17*). More recently, an equally deleterious biallelic p.P81R missense variant was reported $(105,106,107)$. Homozygous individuals in these families exhibited $\mathrm{T} 4$ concentrations of $40-88 \%$ of the lower limit of the normal range and heterozygous carriers were euthyroid (Figs 5A). Where present, the main clinical manifestations comprised growth retardation and delayed bone age. Some affected patients were first diagnosed with $\mathrm{CCH}$ in late childhood or adulthood, but did not exhibit significant neurological deficits suggesting sufficient thyroid hormone production in infancy to prevent overt mental retardation. However, even asymptomatic cases exhibited improved quality of life with levothyroxine therapy (105).

Last year, the first kindred, harbouring a TRHR mutation (p.I131T) which resulted in impaired rather than absent signal transduction was reported. Two homozygotes exhibited either moderate CCH on the basis of FT4 levels or isolated hyperthyrotropinaemia and heterozygotes exhibited isolated hyperthyrotropinaemia, for which the mechanism is unclear (108) (Figs 5A). However, since TRH plays a key role post-translational glycosylation of TSH, which is required to confer normal bioactivity, it is possible that the high TSH in the homozygotes represents a compensatory enhanced production of nonbioactive TSH in response to decreased negative feedback by thyroid hormones. This has previously been noted in central hypothyroidism due to TRH deficiency, where increased amounts of bioinactive TSH may be secreted with immature carbohydrate chains and decreased half-life (109).

TRHR is expressed in both thyrotrophs and lactotrophs; therefore, intravenous TRH usually stimulates both TSH and prolactin peaks. Both these responses were absent in patients with absent TRHR function but preserved with the milder p.I131T mutation (Fig. 5B). One female with the homozygous, p.R17* mutation achieved two normal pregnancies with subsequent lactation prior to her diagnosis, suggesting that TRH action is not obligatory for pregnancy and lactation in humans $(105,106,107,108)$.

\section{IGSF1 mutations}

Loss-of-function mutations in the X-chromosomal immunoglobulin superfamily member 1 (IGSF1) gene are now thought to be the most common genetic abnormality underlying CCH $(110,111)$. Since the initial description of IGSF1 deficiency in eleven European kindreds, more than 30 pathogenic IGSF1 mutations have been described (Fig. 5C). IGSF1 encodes a transmembrane immunoglobulin superfamily glycoprotein and following co-translational proteolysis, its seven carboxyterminal immunoglobulin loops are expressed extracellularly at the plasma membrane. Disease-associated IGSF1 mutations usually impair trafficking and membrane localization of this carboxyterminal domain $(110,111,112)$.

Hemizygous males harbouring IGSF1 mutations exhibit a more severe phenotype than heterozygous females, who may have no overt endocrinopathy. Affected males invariably exhibit $\mathrm{CCH}$, which is usually mild to moderate and associated with a blunted neonatal TSH response to TRH but a low normal response from childhood onward (Figs 5A and B) (112). Additional endocrine abnormalities include disharmonious pubertal development in the majority of cases with delayed pubertal growth spurt and testosterone rise, but normal onset of testicular growth and subsequent macroorchidism in adulthood. Basal prolactin levels are subnormal in more than $60 \%$ males and infrequently, individuals may exhibit transient growth hormone $(\mathrm{GH})$ deficiency in childhood, necessitating $\mathrm{GH}$ replacement. In adulthood, IGF-1 levels are paradoxically in the upper half of the reference range or mildly elevated and acromegaloid features may develop. Heterozygous females harbouring IGSF1 mutations generally exhibit thyroid hormone levels in the lower tertile of the normal range with approximately $20 \%$ fulfilling the criteria for central hypothyroidism. Up to $20 \%$ demonstrate hypoprolactinaemia and four females reported to have required surgery for benign ovarian cysts $(110,111,112)$. A typical feature of kindreds harbouring IGSF1 mutations is the new diagnosis of central hypothyroidism in individuals across three generations, following identification of a young affected proband. It is clear that some children and adults diagnosed during family screening exhibit clinical features of untreated endocrinopathy and benefit from hormone replacement. However, some individuals are apparently healthy, with normal growth and development despite $\mathrm{CCH}$, and in this context, the benefits of levothyroxine treatment remain to be determined $(110,111,112)$.

The precise molecular role of IGSF1 and mechanisms underlying the manifestations of the IGSF1 deficiency syndrome remain unclear. IGSF1 mRNA is expressed in Rathke's pouch and in adult pituitary gland (111); however, a paucity of reliable antibodies has hampered protein expression studies in humans. In rodents, studies using two different antibodies have yielded divergent results, localizing IGSF1 protein either to all cells of the Pou1f1 (Pit1) lineage in murine and rat pituitary $(110,111)$ or (using 
A

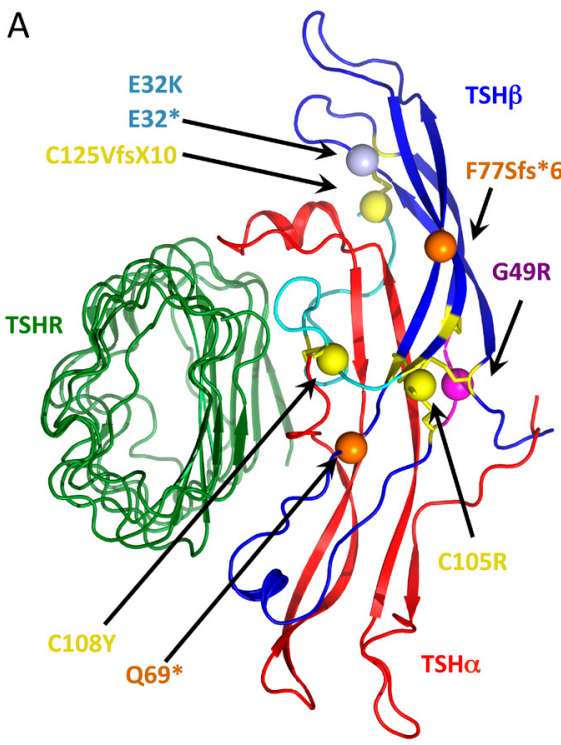

B

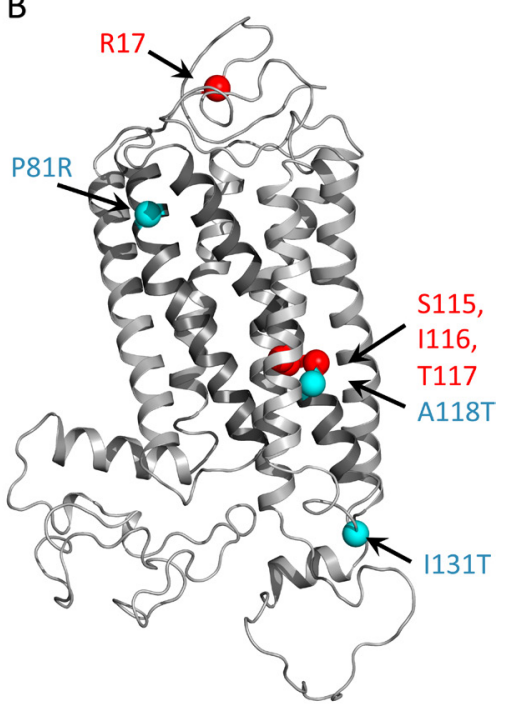

Figure 4

(A) Model for heterodimeric thyroid-stimulating hormone (TSH) bound to the TSH receptor (TSHR) illustrating the position of reported TSHB mutations associated with $\mathrm{CCH}$. The model was generated using PHYRE for predicting TSHbeta subunit (TSH $\beta$ ) structure and was modelled onto FSH-FSHR (1xwd) and the TSHR-K1-70FAB (2xwt) structure using PYMOL. Green: TSHR, Red: TSH alpha subunit (TSH $\alpha, \alpha \mathrm{GSU})$, Blue: TSH $\beta$. Cyan 'seatbelt' region, Yellow: conserved cysteines involved in disulphide bridge formation. Spheres: reported TSHB mutations: C105R; C108Y; C125Vfs*10 (yellow) disrupt disulphide bridges, G49R (purple) is located in the conserved CAGYC region; Q69*; F77Sfs*6 (orange) truncate the protein prematurely and E32* and E32K (light blue) are truncating and missense mutations at the same position. The nomenclature of these mutations follows the most recent HGNC guidelines to include the 20 amino acid signal peptide of TSHB, thus may differ from that cited in the original articles. Nomenclature can be converted to that previously published for missense mutations by subtracting 20 e.g. Q69* new nomenclature $=\mathrm{Q} 49$ * old nomenclature. (B) TRHR structural model generated by homology modelling using the PHYRE server and PYMOL showing the positions of the four previously described mutations associated with central hypothyroidism. The truncating mutation (p.R17* truncating the protein in the extracaellular domain) and the in-frame deletion of 3 amino acids (Ser115-Thr117) are shown in red; missense changes (p.A118T, p.P81R, p.I131T) are shown in blue.

a different, commercially available anti-IGSF1 antibody) to thyrotropes and gonadotropes in rats, but not somatotropes or lactotropes (113). Murine studies in two different IGSF1deficient mouse lines have demonstrated impaired TRH signalling associated with IGSF1 deficiency and decreased pituitary expression of Trhr1 mRNA despite normal TRH synthesis $(110,111)$. This suggests that impaired TRH signalling may underlie the central hypothyroidism seen in IGSF1 deficiency, which would be consistent with the mildmoderate $\mathrm{CCH}$ observed in most humans with hemizygous IGSF1 mutations and blunted neonatal TRH test response. However, the basis for the hypoprolactinaemia and macroorchidism remain unresolved.

\section{TBL1X (transducin $\beta$-like protein 1)}

Loss-of-function missense mutations in TBL1X are the most recently reported genetic cause of isolated $\mathrm{CCH}$.
Like IGSF1, TBL1X is also located on the $\mathrm{X}$ chromosome and eight males harbouring hemizygous mutations, in addition to eleven females harbouring heterozygous mutations were identified in six unrelated kindreds (97). Penetrance was more variable than that in other genetically mediated forms of $\mathrm{CCH}$, with only six males and three females exhibiting FT4 concentrations below the lower limit of the reference range although FT4 levels in affected adults were significantly lower than in controls. Where present, $\mathrm{CCH}$ was isolated, and mild-to-moderate, with normal TRH test responses (Figs 5A and B). Mild sensorineural hearing loss also occurred frequently in affected cases (97). Since TBL1X is an essential component of the main nuclear receptor-corepressor complex (NCoR/SMRT) involved in T3-regulated gene expression, it is hypothesized that, for negatively regulated genes such as TRH and TSHB, TBL1X may play a role in basal activation, as well as ligand-induced transcriptional repression. 
A

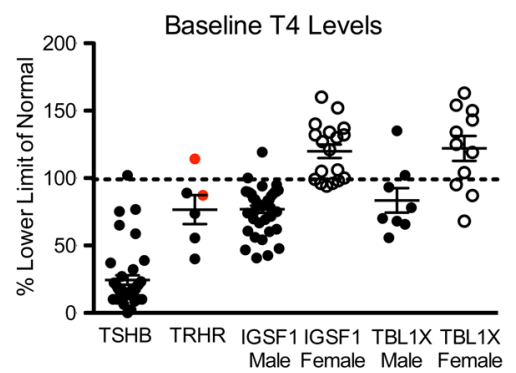

B

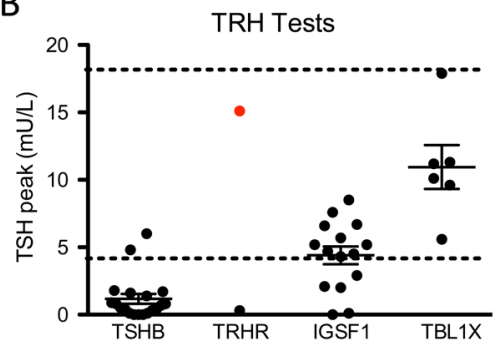

C

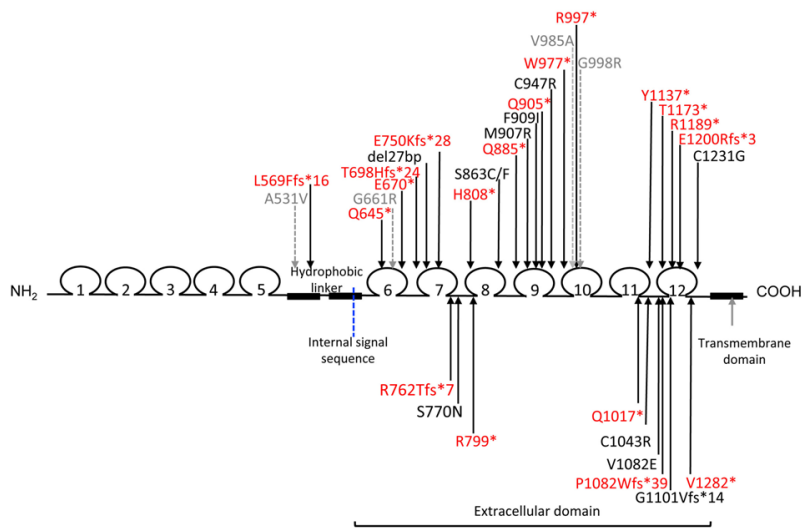

\section{Figure 5}

Comparison of endocrinology in individuals with biallelic TSHB or TRHR mutations (TSHB, TRHR), and hetero- or hemizygous IGSF1 or TBL1X mutations (IGSF1, TBL1X), including all reported mutation carriers for whom numerical biochemical data was available.

(A) Total or FT4 measurements expressed as percentage lower limit of the normal range. (B) Peak TSH response to a standard TRH test excluding 1 IGSF1 deficient case for whom results were discrepant at two different ages (125). IGSF1 data excludes neonates $<1$ month old. Reference ranges are demarcated according to (87). TRHR mutations abolish (black) or partially impair (red) TRHR function. (C) Schematic illustrating the protein domain structure of IGSF1 with the internal signal peptide directing cleavage of the carboxy-terminal domain denoted by a blue line. Positions of naturally-occurring mutations associated with congenital central hypothyroidism are denoted; all are located within the carboxyterminal domain. Mutations in black (missense) and red (truncating mutations) are known or likely to affect membrane trafficking or expression, whereas mutations in grey are associated with a characteristic phenotype but do not affect IGSF1 trafficking in vitro. Four whole gene deletions have also been reported.

Therefore, TBL1X loss-of-function mutations may result in impaired basal activation of these genes.

\section{Screening for primary and central $\mathrm{CH}$}

Screening programmes were first introduced with the aim of eliminating the neurodevelopmental sequelae of late treated $\mathrm{CH}$ and in this respect have been a huge public health success with the majority of primary $\mathrm{CH}$ cases now diagnosed following neonatal screening. Most countries worldwide operate a TSH-based screening strategy where TSH is measured first, usually on a filter paper blood spot sample, and subsequent FT4 or T4 measurement is only performed in infants with a raised TSH. A minority of countries (some state programmes in the United States and Italy, Japan, the Netherlands and Israel) employ a method in which total or FT4 and TSH are either measured simultaneously or in a stepwise manner with T4 measured first. Additional differences in TSH-based screening programme methodology include the timing of the samples (from cord blood to heel prick samples in the second postnatal week), the biochemical assays used and the determined cut points, all of which may confound direct comparison of screening programmes $(114,115)$.

Each CH screening programme has its own advantages and disadvantages. TSH-based programmes are the most sensitive for primary $\mathrm{CH}$, and, by definition, detect both subclinical and overt primary $\mathrm{CH}$. However, $\mathrm{CCH}$ will only be detected by programmes measuring T4 or FT4 
initially or simultaneously with TSH. A disadvantage of this approach is the high false-positive rate, which data from the Netherlands attributes primarily to subnormal total T4 in cases with thyroxine-binding globulin (TBG) deficiency (36\% of false positive cases over a 1-year period) (8). Accordingly, the Netherlands screening strategy includes measurement of TBG as well as TSH, which enables diagnosis of TBG deficiency. However, TBG is only measured in cases with T4-1.6 s.D. or less due to financial and workload constraints $(7,8)$.

Premature birth poses problems for both types of screening programme, especially in infants with very low birth weight. Thyroid dysfunction in preterm infants includes transient hypothyroxinemia of prematurity (low T4 with normal TSH), which may result in many false positive diagnoses on T4-based programmes (accounting for $8 \%$ false positives in the Dutch screening programme) (8). In order to overcome this problem, the Japanese simultaneous TSH/FT4 system defines positive results from newborns with birth weight $<2 \mathrm{~kg}$ as preliminary and repeats the measurements at age 1 month before attributing a definitive diagnosis (116). In the Netherlands, TSH levels are used to recall premature infants, rather than T4 measurements (8). Delayed maturation of the hypothalamic-pituitary-thyroid axis in premature infants may also result in a delayed TSH rise, in which the TSH is initially normal despite primary hypothyroidism but later becomes elevated (117). Since primary CH with delayed TSH rise may therefore evade detection on TSH-based newborn screening programmes, a strategy of second screening is recommended, when the infant is around 1 month old, in order to diagnose $\mathrm{CH}$ in cases with falsenegative screening results at birth. Accordingly, in the UK, infants born at less than 32 weeks undergo a repeat TSH screen aged 4 weeks if the first TSH screen is negative.

In TSH-based screening systems, newborn blood spot TSH screening cutpoints remain a continued subject of discussion, exhibiting widespread disparity even within the United Kingdom where they remain region specific (118). The importance of thyroxine in the myelination of the infant brain is undisputed and more recent functional MRI studies have provided further insight into this (119). However, although the rationale for detecting severe $\mathrm{CH}$ is unequivocal, the benefit to neurodevelopmental outcomes when treating infants with mild to moderately raised TSH and borderline free T4 (FT4) concentrations is more ambiguous. A recent Belgian study found no relationship between cognitive and psychomotor outcomes of preschool children and screening TSH concentrations (120). However, conversely, a large epidemiological study in Australia did suggest a relationship between educational attainment and neonatal TSH. There was a decrease in attainment as the TSH increased from the 75th centile of screening TSH (121). Although absolute TSH concentrations were not given, the distribution of TSH concentrations in screened newborn infants would suggest that the 75 th centile is likely to be below the screening cutpoints of most, if not all, screening laboratories. Both studies have limitations in terms of the chosen developmental assessment tool, the age of child assessment and study design, but the need for future, long-term neurodevelopmental studies is clear.

Primary TSH-based screening strategies do not detect $\mathrm{CCH}$ at birth. Therefore, although moderate-tosevere $\mathrm{CCH}$ may be diagnosed clinically, due to signs suggesting hypothyroidism or due to manifestations of additional pituitary hormone deficits, e.g. micropenis (hypogonadotropic hypogonadism), hypoglycaemia or prolonged neonatal jaundice (central adrenal insufficiency) or postnatal growth failure (GH deficiency), diagnosis and treatment are often significantly delayed $(9,122)$.

There are strong arguments for including $\mathrm{T} 4$ measurement in the $\mathrm{CH}$ screening strategy and the most frequently cited counterarguments (the relative rarity of $\mathrm{CCH}$ and the perception that it is usually mild) are becoming questionable. Combined T4/TSH/ TBG evaluation has yielded an incidence of permanent CCH of 1:16 400 to 1:21 000 in Dutch neonates $(8,9)$ whereas Japanese studies have reported a lower incidence (1:31 000 to $1: 160000$ ), likely reflecting a less sensitive screening approach although differences in ethnicity may also be implicated $(116,123)$. Therefore, although less common than primary $\mathrm{CH}$, the incidence of $\mathrm{CCH}$ in some regions is comparable to that of other conditions included in newborn screening progammes, e.g. phenylketonuria. Moreover, previous perceptions that $\mathrm{CCH}$ is usually mild have been refuted by data from the Netherlands demonstrating that more than $50 \%$ of children with $\mathrm{CCH}$ exhibit moderate or severe hypothyroidism (124). Since it is unequivocal that missed diagnosis of severe $\mathrm{CCH}$, such as in the context of TSHB mutations, or $\mathrm{CCH}$ with additional pituitary hormone deficiencies results in adverse neurodevelopmental outcomes, the potential for delayed diagnosis of moderate-severe $\mathrm{CCH}$ is concerning (98, 124). However, in some contexts (e.g. IGSF1 deficiency), newly diagnosed moderate $\mathrm{CCH}$ in elderly IGSF1 mutation carriers, does not seem to have been associated with obvious developmental sequelae (111). A further benefit of screening for $\mathrm{CCH}$ is its potential to trigger early investigation and detection of concomitant 
pituitary-adrenal and GH deficiencies, for which treatment may prevent life-threatening consequences. Since $75 \%$ of $\mathrm{CCH}$ cases exhibit combined pituitary hormone deficiencies, the significance of this should not be underestimated (5). However, changing from a primary TSH-based screening strategy, to one which identifies $\mathrm{CCH}$ whilst maintaining a high sensitivity for detecting primary $\mathrm{CH}$, is not an insignificant undertaking, especially given the need for early detection of false positive results. Increased complexity of the clinical workload and biochemical methodology as well as cost are all potential barriers to implementation.

\section{Conclusions}

Over the last 40 years, neonatal screening for $\mathrm{CH}$ represents a major public health success, achieving near elimination of associated severe neurodevelopmental delay. In the future, further studies are needed to address the benefits of early detection and treatment of mild $\mathrm{CH}$ and to provide an evidence base for determining optimal TSH screening cutpoints. Additionally, countries operating primary TSH-based screening systems should be encouraged to revisit the cost-benefits of an additional screening step for central $\mathrm{CH}$ in light of current evidence. Although our understanding of the genetic basis for primary and central $\mathrm{CH}$ has improved, the basis for TD in particular remains largely uncharacterized and in genetically ascertained $\mathrm{CH}$, phenotypic variability is poorly accounted for. Further investigation of the contributions of genetic and epigenetic variation, in addition to environmental modifiers, may help elucidate the mechanisms underlying $\mathrm{CH}$ as well as providing novel insights into thyroid development.

\section{Declaration of interest}

The authors declare that there is no conflict of interest that could be perceived as prejudicing the impartiality of this review.

\section{Funding}

Our research is supported by funding from the Wellcome Trust (100585/Z/12/Z to N S) and the National Institute for Health Research Biomedical Research Centre Cambridge (N S).

\section{Acknowledgements}

The authors acknowledge Dr Erik Schoenmakers, University of Cambridge Metabolic Research Laboratories, Wellcome Trust-Medical Research Council Institute of Metabolic Science, Addenbrooke's Hospital, for his work in generating the models for TSH and TRHR used in Fig. 4.

\section{References}

1 Szinnai G. Clinical genetics of congenital hypothyroidism. Endocrine Development 201426 60-78. (https://doi.org/10.1159/000363156)

2 Grasberger H \& Refetoff S. Genetic causes of congenital hypothyroidism due to dyshormonogenesis. Current Opinion in Pediatrics 201123 421-428. (https://doi.org/10.1097/ MOP.0b013e32834726a4)

3 Corbetta C, Weber G, Cortinovis F, Calebiro D, Passoni A, Vigone MC, Beck-Peccoz P, Chiumello G \& Persani L. A 7-year experience with low blood TSH cutoff levels for neonatal screening reveals an unsuspected frequency of congenital hypothyroidism (CH). Clinical Endocrinology 200971 739-745. (https://doi. org/10.1111/j.1365-2265.2009.03568.x)

4 Cherella CE \& Wassner AJ. Congenital hypothyroidism: insights into pathogenesis and treatment. International Journal of Pediatric Endocrinology 20172017 11. (https://doi.org/ 10.1186/s13633-0170051-0)

5 Schoenmakers N, Alatzoglou KS, Chatterjee VK \& Dattani MT. Recent advances in central congenital hypothyroidism. Journal of Endocrinology 2015227 R51-R71. (https://doi.org/10.1530/JOE-15-0341)

6 Zwaveling-Soonawala N, van Trotsenburg ASP \& Verkerk PH. TSH and FT4 Concentrations in congenital central hypothyroidism and mild congenital thyroidal hypothyroidism. Journal of Clinical Endocrinology and Metabolism 2018103 1342-1348. (https://doi. org/10.1210/jc.2017-01577)

7 Lanting CI, van Tijn DA, Loeber JG, Vulsma T, de Vijlder JJ \& Verkerk PH. Clinical effectiveness and cost-effectiveness of the use of the thyroxine/thyroxine-binding globulin ratio to detect congenital hypothyroidism of thyroidal and central origin in a neonatal screening program. Pediatrics 2005116 168-173. (https://doi. org/10.1542/peds.2004-2162)

8 Kempers MJ, Lanting CI, van Heijst AF, van Trotsenburg AS, Wiedijk BM, de Vijlder JJ \& Vulsma T. Neonatal screening for congenital hypothyroidism based on thyroxine, thyrotropin, and thyroxine-binding globulin measurement: potentials and pitfalls. Journal of Clinical Endocrinology and Metabolism 200691 3370-3376. (https://doi.org/10.1210/jc.2006-0058)

9 Beck-Peccoz P, Rodari G, Giavoli C, Lania A. Central hypothyroidism - a neglected thyroid disorder. Nature Reviews Endocrinology 201713 588-598. (https://doi.org/10.1038/nrendo.2017.47)

10 Alm J, Larsson A \& Zetterstrom R. Congenital hypothyroidism in Sweden. Psychomotor development in patients detected by clinical signs and symptoms. Acta Paediatrica Scandinavica 198170 907-912. (https://doi.org/10.1111/j.1651-2227.1981.tb06249.x)

11 Hulse JA. Outcome for congenital hypothyroidism. Archives of Disease in Childhood 198459 23-29. (https://doi.org/10.1136/adc.59.1.23)

12 Fisher DA. Second International Conference on Neonatal Thyroid Screening: progress report. Journal of Pediatrics 1983102 653-654. (https://doi.org/10.1016/S0022-3476(83)80228-5)

13 Langham S, Hindmarsh P, Krywawych S, Peters C. Screening for congenital hypothyroidism: comparison of borderline screening cut-off points and the effect on the number of children treated with levothyroxine. European Thyroid Journal 20132 180-186. (https://doi. org/10.1159/000350039)

14 Albert BB, Cutfield WS, Webster D, Carll J, Derraik JG, Jefferies C, Gunn AJ, Hofman PL. Etiology of increasing incidence of congenital hypothyroidism in New Zealand from 1993-2010. Journal of Clinical Endocrinology and Metabolism 201297 3155-3160. (https://doi. org/10.1210/jc.2012-1562)

15 Barry Y, Bonaldi C, Goulet V, Coutant R, Léger J, Paty AC, Delmas D, Cheillan D \& Roussey M. Increased incidence of congenital hypothyroidism in France from 1982 to 2012: a nationwide multicenter analysis. Annals of Epidemiology 201626 100.e4-105.e4. (https://doi.org/10.1016/j.annepidem.2015.11.005) 
16 Peters C, Brooke I, Heales S, Ifederu A, Langham S, Hindmarsh P $\&$ Cole TJ. Defining the newborn blood spot screening reference interval for TSH: impact of ethnicity. Journal of Clinical Endocrinology and Metabolism 2016101 3445-3449. (https://doi.org/10.1210/ jc.2016-1822)

17 Hinton CF, Harris KB, Borgfeld L, Drummond-Borg M, Eaton R, Lorey F, Therrell BL, Wallace J \& Pass KA. Trends in incidence rates of congenital hypothyroidism related to select demographic factors: data from the United States, California, Massachusetts, New York, and Texas. Pediatrics2010 125 (Supplement 2) S37-S47. (https://doi. org/10.1542/peds.2009-1975D)

18 Vanderpump MP, Lazarus JH, Smyth PP, Laurberg P, Holder RL, Boelaert K, Franklyn JA \& British Thyroid Association UK Iodine Survey Group. Iodine status of UK schoolgirls: a cross-sectional survey. Lancet 2011377 2007-2012. (https://doi.org/10.1016/S01406736(11)60693-4)

19 Fernández LP, López-Márquez A \& Santisteban P. Thyroid transcription factors in development, differentiation and disease. Nature Reviews Endocrinology 201511 29-42. (https://doi. org/10.1038/nrendo.2014.186)

20 Persani L, Calebiro D, Cordella D, Weber G, Gelmini G, Libri D, de Filippis T \& Bonomi M. Genetics and phenomics of hypothyroidism due to TSH resistance. Molecular and Cellular Endocrinology 2010322 72-82. (https://doi.org/10.1016/j.mce.2010.01.008)

21 Dimitri P. The role of GLIS3 in thyroid disease as part of a multisystem disorder. Best Practice and Research Clinical Endocrinology and Metabolism 201731 175-182. (https://doi.org/10.1016/j. beem.2017.04.007)

22 Carré A, Szinnai G, Castanet M, Sura-Trueba S, Tron E, BroutinL'Hermite I, Barat P, Goizet C, Lacombe D, Moutard ML et al. Five new TTF1/NKX2.1 mutations in brain-lung-thyroid syndrome: rescue by PAX8 synergism in one case. Human Molecular Genetics 200918 2266-2276. (https://doi.org/10.1093/hmg/ddp162)

23 Kimura S, Ward JM \& Minoo P. Thyroid-specific enhancer-binding protein/thyroid transcription factor 1 is not required for the initial specification of the thyroid and lung primordia. Biochimie 199981 321-327. (https://doi.org/10.1016/S0300-9084(99)80077-7)

24 Civitareale D, Castelli MP, Falasca P \& Saiardi A. Thyroid transcription factor 1 activates the promoter of the thyrotropin receptor gene. Molecular Endocrinology 19937 1589-1595.

25 Kusakabe T, Kawaguchi A, Hoshi N, Kawaguchi R, Hoshi S \& Kimura S. Thyroid-specific enhancer-binding protein/NKX2.1 is required for the maintenance of ordered architecture and function of the differentiated thyroid. Molecular Endocrinology 200620 1796-1809. (https://doi.org/10.1210/me.2005-0327)

2626 de Filippis T, Marelli F, Vigone MC, Di Frenna M, Weber G \& Persani L. Novel NKX2-1 frameshift mutations in patients with atypical phenotypes of the brain-lung-thyroid syndrome. European Thyroid Journal 20143 227-233. (https://doi.org/10.1159/000366015)

27 Thorwarth A, Schnittert-Hübener S, Schrumpf P, Müller I, Jyrch S, Dame C, Biebermann H, Kleinau G, Katchanov J, Schuelke M et al. Comprehensive genotyping and clinical characterisation reveal 27 novel NKX2-1 mutations and expand the phenotypic spectrum. Journal of Medical Genetics 201451 375-387. (https://doi. org/10.1136/jmedgenet-2013-102248)

28 Shinohara H, Takagi M, Ito K, Suzuki E, Fukuzawa R \& Hasegawa T. A novel mutation in NKX2.1 shows dominant-negative effects only in the presence of PAX8. Thyroid. 201828 1071-1073. (https://doi.org/ 10.1089/thy.2017.0481)

29 Francis-Lang H, Price M, Polycarpou-Schwarz M \& Di Lauro R. Cell-type-specific expression of the rat thyroperoxidase promoter indicates common mechanisms for thyroid-specific gene expression. Molecular and Cellular Biology 199212 576-588. (https://doi. org/10.1128/MCB.12.2.576)

30 Ohno M, Zannini M, Levy O, Carrasco N \& di Lauro R. The paireddomain transcription factor Pax8 binds to the upstream enhancer of the rat sodium/iodide symporter gene and participates in both thyroid-specific and cyclic-AMP-dependent transcription. Molecular and Cellular Biology 199919 2051-2060. (https://doi.org/10.1128/ MCB.19.3.2051)

31 Parlato R, Rosica A, Rodriguez-Mallon A, Affuso A, Postiglione MP, Arra C, Mansouri A, Kimura S, Di Lauro R \& De Felice M. An integrated regulatory network controlling survival and migration in thyroid organogenesis. Developmental Biology 2004276 464-475. (https://doi.org/10.1016/j.ydbio.2004.08.048)

32 Marotta P, Amendola E, Scarfò M, De Luca P, Zoppoli P, Amoresano A, De Felice M \& Di Lauro R. The paired box transcription factor Pax8 is essential for function and survival of adult thyroid cells. Molecular and Cellular Endocrinology 2014396 26-36. (https://doi. org/10.1016/j.mce.2014.08.004)

33 Hermanns P, Grasberger H, Cohen R, Freiberg C, Dörr HG, Refetoff S \& Pohlenz J. Two cases of thyroid dysgenesis caused by different novel PAX8 mutations in the DNA-binding region: in vitro studies reveal different pathogenic mechanisms. Thyroid 201323 791-796. (https://doi.org/10.1089/thy.2012.0141)

34 Narumi S, Araki S, Hori N, Muroya K, Yamamoto Y, Asakura Y, Adachi M \& Hasegawa T. Functional characterization of four novel PAX8 mutations causing congenital hypothyroidism: new evidence for haploinsufficiency as a disease mechanism. European Journal of Endocrinology 2012167 625-632. (https://doi.org/10.1530/EJE-120410)

35 Ramos HE, Carré A, Chevrier L, Szinnai G, Tron E, Cerqueira TL, Léger J, Cabrol S, Puel O, Queinnec C et al. Extreme phenotypic variability of thyroid dysgenesis in six new cases of congenital hypothyroidism due to PAX8 gene loss-of-function mutations. European Journal of Endocrinology 2014171 499-507. (https://doi. org/10.1530/EJE-13-1006)

36 Montanelli L \& Tonacchera M. Genetics and phenomics of hypothyroidism and thyroid dys- and agenesis due to PAX8 and TTF1 mutations. Molecular and Cellular Endocrinology 2010322 64-71. (https://doi.org/10.1016/j.mce.2010.03.009)

37 De Felice M, Ovitt C, Biffali E, Rodriguez-Mallon A, Arra C, Anastassiadis K, Macchia PE, Mattei MG, Mariano A, Schöler H et al. A mouse model for hereditary thyroid dysgenesis and cleft palate. Nature Genetics 199819 395-398. (https://doi.org/10.1038/1289)

38 Fagman H \& Nilsson M. Morphogenesis of the thyroid gland. Molecular and Cellular Endocrinology 2010323 35-54. (https://doi. org/10.1016/j.mce.2009.12.008)

39 Castanet M \& Polak M. Spectrum of human Foxe1/TTF2 mutations. Hormone Research in Paediatrics 201073 423-429. (https://doi. org/10.1159/000281438)

40 Carré A, Hamza RT, Kariyawasam D, Guillot L, Teissier R, Tron E, Castanet M, Dupuy C, El Kholy M \& Polak M. A novel FOXE1 mutation (R73S) in Bamforth-Lazarus syndrome causing increased thyroidal gene expression. Thyroid 201424 649-654. (https://doi. org/10.1089/thy.2013.0417)

41 Kang HS, Kumar D, Liao G, Lichti-Kaiser K, Gerrish K, Liao XH, Refetoff S, Jothi R \& Jetten AM. GLIS3 is indispensable for TSH/ TSHR-dependent thyroid hormone biosynthesis and follicular cell proliferation. Journal of Clinical Investigation $2017 \mathbf{1 2 7} 4326-4337$. (https://doi.org/ 10.1172/JCI94417)

42 Cassio A, Nicoletti A, Rizzello A, Zazzetta E, Bal M \& Baldazzi L. Current loss-of-function mutations in the thyrotropin receptor gene: when to investigate, clinical effects, and treatment. Journal of Clinical Research in Pediatric Endocrinology 20135 29-39. (https://doi. org/10.4274/jcrpe.864)

43 Cangul H, Aycan Z, Saglam H, Forman JR, Cetinkaya S, Tarim O, Bober E, Cesur Y, Kurtoglu S, Darendeliler F et al. TSHR is the main causative locus in autosomal recessively inherited thyroid dysgenesis. Journal of Pediatric Endocrinology and Metabolism 201225 419-426.

44 Clifton-Bligh RJ, Gregory JW, Ludgate M, John R, Persani L, Asteria C, Beck-Peccoz P \& Chatterjee VK. Two novel mutations in the 
thyrotropin (TSH) receptor gene in a child with resistance to TSH. Journal of Clinical Endocrinology and Metabolism 199782 1094-1100.

45 Sunthornthepvarakui T, Gottschalk ME, Hayashi Y \& Refetoff S. Brief report: resistance to thyrotropin caused by mutations in the thyrotropin-receptor gene. New England Journal of Medicine 1995332 155-160. (https://doi.org/10.1056/NEJM199501193320305)

46 Tenenbaum-Rakover Y, Almashanu S, Hess O, Admoni O, HagDahood Mahameed A, Schwartz N, Allon-Shalev S, Bercovich D $\&$ Refetoff S. Long-term outcome of loss-of-function mutations in thyrotropin receptor gene. Thyroid 201525 292-299. (https://doi. org/10.1089/thy.2014.0311)

47 Vigone MC, Di Frenna M, Guizzardi F, Gelmini G, de Filippis T, Mora S, Caiulo S, Sonnino M, Bonomi M, Persani L et al. Mild TSH resistance: clinical and hormonal features in childhood and adulthood. Clinical Endocrinology 201787 587-596. (https://doi. org/10.1111/cen.13387)

48 Dentice M, Cordeddu V, Rosica A, Ferrara AM, Santarpia L, Salvatore D, Chiovato L, Perri A, Moschini L, Fazzini C et al. Missense mutation in the transcription factor NKX2-5: a novel molecular event in the pathogenesis of thyroid dysgenesis. Journal of Clinical Endocrinology and Metabolism 200691 1428-1433. (https://doi. org/10.1210/jc.2005-1350)

49 van Engelen K, Mommersteeg MT, Baars MJ, Lam J, Ilgun A, van Trotsenburg AS, Smets AM, Christoffels VM, Mulder BJ \& Postma AV. The ambiguous role of NKX2-5 mutations in thyroid dysgenesis. PLoS ONE 20127 e52685. (https://doi.org/10.1371/journal.pone.0052685)

50 Porazzi P, Marelli F, Benato F, de Filippis T, Calebiro D, Argenton F, Tiso N \& Persani L. Disruptions of global and JAGGED1-mediated notch signaling affect thyroid morphogenesis in the zebrafish. Endocrinology 2012153 5645-5658. (https://doi.org/10.1210/ en.2011-1888)

51 de Filippis T, Marelli F, Nebbia G, Porazzi P, Corbetta S, Fugazzola L, Gastaldi R, Vigone MC, Biffanti R, Frizziero D et al. JAG1 loss-offunction variations as a novel predisposing event in the pathogenesis of congenital thyroid defects. Journal of Clinical Endocrinology and Metabolism 2016101 861-870. (https://doi.org/10.1210/jc.20153403)

52 de Filippis T, Gelmini G, Paraboschi E, Vigone MC, Di Frenna M, Marelli F, Bonomi M, Cassio A, Larizza D, Moro M et al. A frequent oligogenic involvement in congenital hypothyroidism. Human Molecular Genetics 201726 2507-2514. (https://doi.org/10.1093/ $\mathrm{hmg} / \mathrm{ddx} 145)$

53 Carré A, Stoupa A, Kariyawasam D, Gueriouz M, Ramond C, Monus T, Léger J, Gaujoux S, Sebag F, Glaser N et al. Mutations in BOREALIN cause thyroid dysgenesis. Human Molecular Genetics 2017 26 599-610. (https://doi.org/10.1093/hmg/ddw419)

54 Opitz R, Hitz MP, Vandernoot I, Trubiroha A, Abu-Khudir R, Samuels M, Désilets V, Costagliola S, Andelfinger G \& Deladoëy J. Functional zebrafish studies based on human genotyping point to netrin-1 as a link between aberrant cardiovascular development and thyroid dysgenesis. Endocrinology 2015156 377-388. (https://doi. org/10.1210/en.2014-1628)

55 Targovnik HM, Citterio CE, Rivolta CM. Iodide handling disorders (NIS, TPO, TG, IYD). Best Practice and Research Clinical Endocrinology and Metabolism 201731 195-212. (https://doi.org/10.1016/j. beem.2017.03.006)

56 Bakker B, Bikker H, Vulsma T, de Randamie JS, Wiedijk BM \& De Vijlder JJ. Two decades of screening for congenital hypothyroidism in The Netherlands: TPO gene mutations in total iodide organification defects (an update). Journal of Clinical Endocrinology and Metabolism 200085 3708-3712. (https://doi.org/10.1210/jcem.85.10.6878)

57 Cangul H, Aycan Z, Olivera-Nappa A, Saglam H, Schoenmakers NA, Boelaert K, Cetinkaya S, Tarim O, Bober E, Darendeliler F et al. Thyroid dyshormonogenesis is mainly caused by TPO mutations in consanguineous community. Clinical Endocrinology 201379 275-281. (https://doi.org/10.1111/cen.12127)
58 Narumi S, Muroya K, Asakura Y, Aachi M \& Hasegawa T. Molecular basis of thyroid dyshormonogenesis: genetic screening in population-based Japanese patients. Journal of Clinical Endocrinology and Metabolism 201196 E1838-E1842. (https://doi.org/10.1210/ jc.2011-1573)

59 Park KJ, Park HK, Kim YJ, Lee KR, Park JH, Park JH, Park HD, Lee SY \& Kim JW. DUOX2 Mutations Are Frequently Associated With Congenital Hypothyroidism in the Korean Population. Annals of Laboratory Medicine 201636 145-153. (https://doi.org/10.3343/ alm.2016.36.2.145)

60 Muzza M, Rabbiosi S, Vigone MC, Zamproni I, Cirello V, Maffini MA, Maruca K, Schoenmakers N, Beccaria L, Gallo F et al. The clinical and molecular characterization of patients with dyshormonogenic congenital hypothyroidism reveals specific diagnostic clues for DUOX2 defects. Journal of Clinical Endocrinology and Metabolism 2014 99 E544-E553. (https://doi.org/10.1210/jc.2013-3618)

61 Fraser GR. Association of congenital deafness with goitre (Pendred's syndrome): a study of 207 families. Annals of Human Genetics 1965 28 411-422.

62 Reardon W, Coffey R, Phelps PD, Luxon LM, Stephens D, KendallTaylor P, Britton KE, Grossman A \& Trembath R. Pendred syndrome 100 years of underascertainment? Queensland Journal of Medicine 1997 $90443-447$.

63 Donko A, Ruisanchez E \& Orient A. Urothelial cells produce hydrogen peroxide through the activation of Duox1. Free Radical Biology and Medicine 201049 2040-2048. (https://doi.org/10.1016/j. freeradbiomed.2010.09.027)

64 Grasberger H \& Refetoff S. Identification of the maturation factor for dual oxidase. Evolution of an eukaryotic operon equivalent. Journal of Biological Chemistry 2006281 18269-18272. (https://doi. org/10.1074/jbc.C600095200)

65 De Marco G, Agretti P, Montanelli L, Di Cosmo C, Bagattini B, De Servi M, Ferrarini E, Dimida A, Freitas Ferreira AC, Molinaro A et al. Identification and functional analysis of novel dual oxidase 2 (DUOX2) mutations in children with congenital or subclinical hypothyroidism. Journal of Clinical Endocrinology and Metabolism 2011 96 E1335-E1339. (https://doi.org/10.1210/jc.2010-2467)

66 Grasberger H, De Deken X, Miot F, Pohlenz J \& Refetoff S. Missense mutations of dual oxidase 2 (DUOX2) implicated in congenital hypothyroidism have impaired trafficking in cells reconstituted with DUOX2 maturation factor. Molecular Endocrinology 200721 1408-1421. (https://doi.org/10.1210/me.2007-0018)

67 Hoste C, Rigutto S, Van Vliet G, Miot F \& De Deken X. Compound heterozygosity for a novel hemizygous missense mutation and a partial deletion affecting the catalytic core of the $\mathrm{H} 2 \mathrm{O} 2$ generating enzyme DUOX2 associated with transient congenital hypothyroidism. Human Mutation 201031 E1304-E1319. (https:// doi.org/10.1002/humu.21227)

68 Moreno JC, Bikker H, Kempers MJ, van Trotsenburg AS, Baas F, de Vijlder JJ, Vulsma T, Ris-Stalpers C. Inactivating mutations in the gene for thyroid oxidase 2 (THOX2) and congenital hypothyroidism. New England Journal of Medicine 2002347 95-102. (https://doi. org/10.1056/NEJMoa012752)

69 Muzza M \& Fugazzola L. Disorders of $\mathrm{H} 2 \mathrm{O} 2$ generation. Best Practice and Research Clinical Endocrinology and Metabolism 201731 225-240. (https://doi.org/10.1016/j.beem.2017.04.006)

70 Srichomkwun P, Takamatsu J, Nickerson DA, Bamshad MJ, Chong JX $\&$ Refetoff S. DUOX2 Gene mutation manifesting as resistance to thyrotropin phenotype. Thyroid 201727 129-131. (https://doi. org/10.1089/thy.2016.0469)

71 Kizys MML, Louzada RA, Mitne-Neto M, Jara JR, Furuzawa GK, de Carvalho DP, Dias-da-Silva MR, Nesi-França S, Dupuy C \& Maciel RMB. DUOX2 mutations are associated with congenital hypothyroidism with ectopic thyroid gland. Journal of Clinical Endocrinology and Metabolism 2017102 4060-4071. (https://doi. org/10.1210/jc.2017-00832) 
72 Aycan Z, Cangul H, Muzza M, Bas VN, Fugazzola L, Chatterjee VK, Persani L \& Schoenmakers N. Digenic DUOX1 and DUOX2 mutations in cases with congenital hypothyroidism. Journal of Clinical Endocrinology and Metabolism 2017102 3085-3090. (https:// doi.org/10.1210/jc.2017-00529)

73 Johnson KR, Marden CC, Ward-Bailey P, Gagnon LH, Bronson RT \& Donahue LR. Congenital hypothyroidism, dwarfism, and hearing impairment caused by a missense mutation in the mouse dual oxidase 2 gene, Duox2. Molecular Endocrinology 200721 1593-1602.

74 Liu S, Liu L, Niu X, Lu D, Xia H, Yan S. A novel missense mutation (I26M) in DUOXA2 causing congenital goiter hypothyroidism impairs NADPH oxidase activity but not protein expression. Journal of Clinical Endocrinology and Metabolism 2015100 1225-1229. (https://doi.org/10.1210/jc.2014-3964)

75 Zamproni I, Grasberger H, Cortinovis F, Vigone MC, Chiumello G, Mora S, Onigata K, Fugazzola L, Refetoff S, Persani L et al. Biallelic inactivation of the dual oxidase maturation factor 2 (DUOXA2) gene as a novel cause of congenital hypothyroidism. Journal of Clinical Endocrinology and Metabolism 200893 605-610. (https://doi. org/10.1210/jc.2007-2020)

76 Moreno JC, Klootwijk W, van Toor H, Pinto G, D'Alessandro M, Lèger A, Goudie D, Polak M, Grüters A \& Visser TJ. Mutations in the iodotyrosine deiodinase gene and hypothyroidism. New England Journal of Medicine 2008358 1811-1818. (https://doi.org/10.1056/ NEJMoa0706819)

77 Szinnai G, Kosugi S, Derrien C, Lucidarme N, David V, Czernichow P $\&$ Polak M. Extending the clinical heterogeneity of iodide transport defect (ITD): a novel mutation R124H of the sodium/iodide symporter gene and review of genotype-phenotype correlations in ITD. Journal of Clinical Endocrinology and Metabolism 200691 1199-1204. (https://doi.org/10.1210/jc.2005-1832)

78 Perry R, Heinrichs C, Bourdoux P, Khoury K, Szöts F, Dussault JH, Vassart G \& Van Vliet G. Discordance of monozygotic twins for thyroid dysgenesis: implications for screening and for molecular pathophysiology. Journal of Clinical Endocrinology and Metabolism 200287 4072-4077. (https://doi.org/10.1210/jc.2001-011995)

79 Devos H, Rodd C, Gagné N, Laframboise R \& Van Vliet G. A search for the possible molecular mechanisms of thyroid dysgenesis: sex ratios and associated malformations. Journal of Clinical Endocrinology and Metabolism 199984 2502-2506. (https://doi.org/10.1210/ jcem.84.7.5831)

80 Castanet M, Lyonnet S, Bonaïti-Pellié C, Polak M, Czernichow P \& Léger J. Familial forms of thyroid dysgenesis among infants with congenital hypothyroidism. New England Journal of Medicine 2000 343 441-442. (https://doi.org/10.1056/NEJM200008103430614)

81 Léger J, Marinovic D, Garel C, Bonaïti-Pellié C, Polak M \& Czernichow P. Thyroid developmental anomalies in first degree relatives of children with congenital hypothyroidism. Journal of Clinical Endocrinology and Metabolism 200287 575-580.

82 Kreisner E, Neto EC \& Gross JL. High prevalence of extrathyroid malformations in a cohort of Brazilian patients with permanent primary congenital hypothyroidism. Thyroid 200515 165-169. (https://doi.org/10.1089/thy.2005.15.165)

83 Stoppa-Vaucher S, Van Vliet G \& Deladoëy J. Variation by ethnicity in the prevalence of congenital hypothyroidism due to thyroid dysgenesis. Thyroid 201121 13-18. (https://doi.org/10.1089/ thy.2010.0205)

84 Van Vliet G, Deladoëy J. Sublingual thyroid ectopy: similarities and differences with Kallmann syndrome. F100OPrime Reports 2015720.

85 Abu-Khudir R, Paquette J, Lefort A, Libert F, Chanoine JP, Vassart G $\&$ Deladoëy J. Transcriptome, methylome and genomic variations analysis of ectopic thyroid glands. PLoS ONE 20105 e13420. (https:// doi.org/10.1371/journal.pone.0013420)

86 Magne F, Serpa R, Van Vliet G, Samuels ME \& Deladoëy J. Somatic mutations are not observed by exome sequencing of lymphocyte DNA from monozygotic twins discordant for congenital hypothyroidism due to thyroid dysgenesis. Hormone Research in Paediatrics 201583 79-85. (https://doi.org/10.1159/000365393)

87 Narumi S, Yoshida A, Muroya K, Asakura Y, Adachi M, Fukuzawa R, Kameyama K, Hasegawa T. PAX8 mutation disturbing thyroid follicular growth: a case report. Journal of Clinical Endocrinology and Metabolism 201196 E2039-E2044. (https://doi.org/10.1210/jc.2011-1114)

88 Magne F, Ge B, Larrivée-Vanier S, Van Vliet G, Samuels ME, Pastinen T \& Deladoëy J. Demonstration of autosomal monoallelic expression in thyroid tissue assessed by whole-exome and bulk RNA sequencing. Thyroid 201626 852-859. (https://doi.org/10.1089/ thy.2016.0009)

89 Fugazzola L, Cerutti N, Mannavola D, Vannucchi G, Fallini C, Persani L \& Beck-Peccoz P. Monoallelic expression of mutant thyroid peroxidase allele causing total iodide organification defect. Journal of Clinical Endocrinology and Metabolism 200388 3264-3271. (https:// doi.org/10.1210/jc.2002-021377)

90 Thorwarth A, Mueller I, Biebermann H, Ropers HH, Grueters A, Krude H \& Ullmann R. Screening chromosomal aberrations by array comparative genomic hybridization in 80 patients with congenital hypothyroidism and thyroid dysgenesis. Journal of Clinical Endocrinology and Metabolism 201095 3446-3452. (https://doi. org/10.1210/jc.2009-2195)

91 Amendola E, De Luca P, Macchia PE, Terracciano D, Rosica A, Chiappetta G, Kimura S, Mansouri A, Affuso A, Arra C et al. A mouse model demonstrates a multigenic origin of congenital hypothyroidism. Endocrinology 2005146 5038-5047. (https://doi. org/10.1210/en.2005-0882)

92 Nicholas AK, Serra EG, Cangul H, Alyaarubi S, Ullah I, Schoenmakers E, Deeb A, Habeb AM, Almaghamsi M, Peters C et al. Comprehensive screening of eight known causative genes in congenital hypothyroidism with gland-in-situ. Journal of Clinical Endocrinology and Metabolism 2016101 4521-4531. (https://doi. org/10.1210/jc.2016-1879)

93 Kühnen P, Turan S, Fröhler S, Güran T, Abali S, Biebermann H, Bereket A, Grüters A, Chen W \& Krude H. Identification of PENDRIN (SLC26A4) mutations in patients with congenital hypothyroidism and "apparent" thyroid dysgenesis. Journal of Clinical Endocrinology and Metabolism 201499 E169-E176. (https://doui.org/10.1210/ jc.2013-2619)

94 Nilsson M, Fagman H. Development of the thyroid gland. Development 2017144 2123-2140. (https://doi.org/10.1242/ dev.145615)

95 Antonica F, Kasprzyk DF, Opitz R, Iacovino M, Liao XH, Dumitrescu AM, Refetoff S, Peremans K, Manto M, Kyba M et al. Generation of functional thyroid from embryonic stem cells. Nature 2012491 66-71. (https://doi.org/10.1038/nature11525)

96 Kurmann AA, Serra M, Hawkins F, Rankin SA, Mori M, Astapova I, Ullas S, Lin S, Bilodeau M, Rossant J et al. Regeneration of thyroid function by transplantation of differentiated pluripotent stem cells. Cell Stem Cell 201517 527-542. (https://doi.org/10.1016/j. stem.2015.09.004)

97 Heinen CA, Losekoot M, Sun Y, Watson PJ, Fairall L, Joustra SD, Zwaveling-Soonawala N, Oostdijk W, van den Akker EL, Alders $\mathrm{M}$ et al. Mutations in TBL1X are associated with central hypothyroidism. Journal of Clinical Endocrinology and Metabolism 2016 101 4564-4573. (https://doi.org/10.1210/jc.2016-2531)

98 Nicholas AK, Jaleel S, Lyons G, Schoenmakers E, Dattani MT, Crowne E, Bernhard B, Kirk J, Roche EF, Chatterjee VK et al. Molecular spectrum of TSH $\beta$ subunit gene defects in central hypothyroidism in the UK and Ireland. Clinical Endocrinology 2017 86 410-418. (https://doi.org/10.1111/cen.13149)

99 Medeiros-Neto G, Herodotou DT, Rajan S, Kommareddi S, de Lacerda L, Sandrini R, Boguszewski MC, Hollenberg AN, Radovick S \& Wondisford FE. A circulating, biologically inactive thyrotropin caused by a mutation in the beta subunit gene. Journal of Clinical Investigation 199697 1250-1256. (https://doi.org/10.1172/JCI118540) 
100 Baquedano MS, Ciaccio M, Dujovne N, Herzovich V, Longueira Y, Warman DM, Rivarola MA \& Belgorosky A. Two novel mutations of the TSH-beta subunit gene underlying congenital central hypothyroidism undetectable in neonatal TSH screening. Journal of Clinical Endocrinology and Metabolism 201095 E98-E103. (https://doi. org/10.1210/jc.2010-0223)

101 1Pohlenz J, Dumitrescu A, Aumann U, Koch G, Melchior R, Prawitt D $\&$ Refetoff $\mathrm{S}$. Congenital secondary hypothyroidism caused by exon skipping due to a homozygous donor splice site mutation in the TSHbeta-subunit gene. Journal of Clinical Endocrinology and Metabolism 200287 336-339. (https://doi.org/10.1210/jcem.87.1.8154)

102 Hermanns P, Couch R, Leonard N, Klotz C \& Pohlenz J. A novel deletion in the thyrotropin Beta-subunit gene identified by array comparative genomic hybridization analysis causes central congenital hypothyroidism in a boy originating from Turkey. Hormone Research in Paediatrics 201482 201-205. (https://doi. org/10.1159/000362413)

103 Bonomi M, Proverbio MC, Weber G, Chiumello G, Beck-Peccoz P \& Persani L. Hyperplastic pituitary gland, high serum glycoprotein hormone alpha-subunit, and variable circulating thyrotropin (TSH) levels as hallmark of central hypothyroidism due to mutations of the TSH beta gene. Journal of Clinical Endocrinology and Metabolism 2001 86 1600-1604.

104 Heinrichs C, Parma J, Scherberg NH et al. Congenital central isolated hypothyroidism caused by a homozygous mutation in the TSH-beta subunit gene. Thyroid 200010 387-391. (https://doi.org/10.1089/ thy.2000.10.387)

105 Bonomi M, Busnelli M, Beck-Peccoz P, Costanzo D, Antonica F, Dolci C, Pilotta A, Buzi F \& Persani L. A family with complete resistance to thyrotropin-releasing hormone. New England Journal of Medicine 2009360 731-734. (https://doi.org/10.1056/NEJMc0808557)

106 Collu R, Tang J, Castagné J, Lagacé G, Masson N, Huot C, Deal C, Delvin E, Faccenda E, Eidne KA et al. A novel mechanism for isolated central hypothyroidism: inactivating mutations in the thyrotropinreleasing hormone receptor gene. Journal of Clinical Endocrinology and Metabolism 199782 1561-1565.

107 Koulouri O, Nicholas AK, Schoenmakers E, Mokrosinski J, Lane F, Cole T, Kirk J, Farooqi IS, Chatterjee VK, Gurnell M et al. A novel thyrotropin-releasing hormone receptor missense mutation (P81R) in central congenital hypothyroidism. Journal of Clinical Endocrinology and Metabolism 2016101 847-851. (https://doi.org/10.1210/jc.2015-3916)

108 García M, González de Buitrago J, Jiménez-Rosés M, Pardo L, Hinkle PM \& Moreno JC. Central hypothyroidism due to a TRHR mutation causing impaired ligand affinity and transactivation of Gq Journal of Clinical Endocrinology and Metabolism 2017102 2433-2442.

109 Persani L. Hypothalamic thyrotropin-releasing hormone and thyrotropin biological activity. Thyroid 19988 941-946. (https://doi. org/10.1089/thy.1998.8.941)

110 Bernard DJ, Brûlé E, Smith CL, Joustra SD, Wit JM. From consternation to revelation: discovery of a role for IGSF1 in pituitary control of thyroid function. Journal of the Endocrine Society 20182 220-231. (https://doi.org/10.1210/js.2017-00478)

111 Sun Y, Bak B, Schoenmakers N, van Trotsenburg AS, Oostdijk W, Voshol P, Cambridge E, White JK, le Tissier P, Gharavy SN et al. Loss-of-function mutations in IGSF1 cause an X-linked syndrome of central hypothyroidism and testicular enlargement. Nature Genetics 201244 1375-1381. (https://doi.org/10.1038/ng.2453)

112 Joustra SD, Heinen CA, Schoenmakers N, Bonomi M, Ballieux BE, Turgeon MO, Bernard DJ, Fliers E, van Trotsenburg AS, Losekoot M et al. IGSF1 deficiency: lessons from an extensive case series and recommendations for clinical management. Journal of Clinical
Endocrinology and Metabolism 2016101 1627-1636. (https://doi. org/10.1210/jc.2015-3880)

113 García M, Barrio R, García-Lavandeira M, Garcia-Rendueles AR, Escudero A, Díaz-Rodríguez E, Gorbenko Del Blanco D, Fernández A, de Rijke YB, Vallespín E et al. The syndrome of central hypothyroidism and macroorchidism: IGSF1 controls TRHR and FSHB expression by differential modulation of pituitary TGF $\beta$ and Activin pathways. Scientific Reports 20177 42937. (https://doi. org/10.1038/srep42937)

114 Ford G \& LaFranchi SH. Screening for congenital hypothyroidism: a worldwide view of strategies. Best Practice and Research Clinical Endocrinology and Metabolism 201428 175-187. (https://doi. org/10.1016/j.beem.2013.05.008)

115 Kilberg MJ, Rasooly IR, LaFranchi SH, Bauer AJ \& Hawkes CP. Newborn screening in the US may miss mild persistent hypothyroidism. Journal of Pediatrics 2018192 204-208. (https://doi. org/10.1016/j.jpeds.2017.09.003)

116 Adachi M, Soneda A, Asakura Y, Muroya K, Yamagami Y \& Hirahara F. Mass screening of newborns for congenital hypothyroidism of central origin by free thyroxine measurement of blood samples on filter paper. European Journal of Endocrinology 2012166 829-838. (https://doi.org/10.1530/EJE-11-0653)

117 Wassner AJ \& Brown RS. Hypothyroidism in the newborn period. Current Opinion in Endocrinology, Diabetes and Obesity 201320 449-454. (https://doi.org/10.1097/01.med.0000433063.78799.c2)

118 Lain S, Trumpff C, Grosse SD, Olivieri A \& Van Vliet G. Are lower TSH cutoffs in neonatal screening for congenital hypothyroidism warranted? European Journal of Endocrinology/European Federation of Endocrine Societies 2017177 D1-D12. (https://doi.org/10.1530/EJE-17-0107)

119 Rovet JF. The role of thyroid hormones for brain development and cognitive function. Endocrine Development 201426 26-43. (https:// doi.org/10.1159/000363153)

120 Trumpff C, De Schepper J, Vanderfaeillie J, Vercruysse N, Van Oyen H, Moreno-Reyes R, Tafforeau J, Vanderpas J \& Vandevijvere S. Thyroid-stimulating hormone (TSH) concentration at birth in belgian neonates and cognitive development at preschool age. Nutrients 20157 9018-9032. (https://doi.org/10.3390/nu7115450)

121 Lain SJ, Bentley JP, Wiley V, Roberts CL, Jack M, Wilcken B, Nassar N. Association between borderline neonatal thyroid-stimulating hormone concentrations and educational and developmental outcomes: a population-based record-linkage study. Lancet Diabetes and Endocrinology 20164 756-765. (https://doi.org/10.1016/S22138587(16)30122-X)

122 Nebesio TD, McKenna MP, Nabhan ZM \& Eugster EA. Newborn screening results in children with central hypothyroidism. Journal of Pediatrics 2010156 990-993. (https://doi.org/10.1016/j. jpeds.2009.12.011)

123 Asakura Y, Tachibana K, Adachi M, Suwa S \& Yamagami Y. Hypothalamo-pituitary hypothyroidism detected by neonatal screening for congenital hypothyroidism using measurement of thyroid-stimulating hormone and thyroxine. Acta Paediatrica 2002 91 172-177. (https://doi.org/10.1080/080352502317285171)

124 Zwaveling-Soonawala N, van Trotsenburg AS \& Verkerk PH. The severity of congenital hypothyroidism of central origin should not be underestimated. Journal of Clinical Endocrinology and Metabolism 2015100 E297-E300. (https://doi.org/10.1210/jc.2014-2871)

125 Nakamura A, Bak B, Silander TL, Lam J, Hotsubo T, Yorifuji T, Ishizu K, Bernard DJ \& Tajima T. Three novel IGSF1 mutations in four Japanese patients with X-linked congenital central hypothyroidism. Journal of Clinical Endocrinology and Metabolism 2013 98 E1682-E1691. (https://doi.org/10.1210/jc.2013-1224)
Received 1 May 2018

Revised version received 15 August 2018

Accepted 24 September 2018 